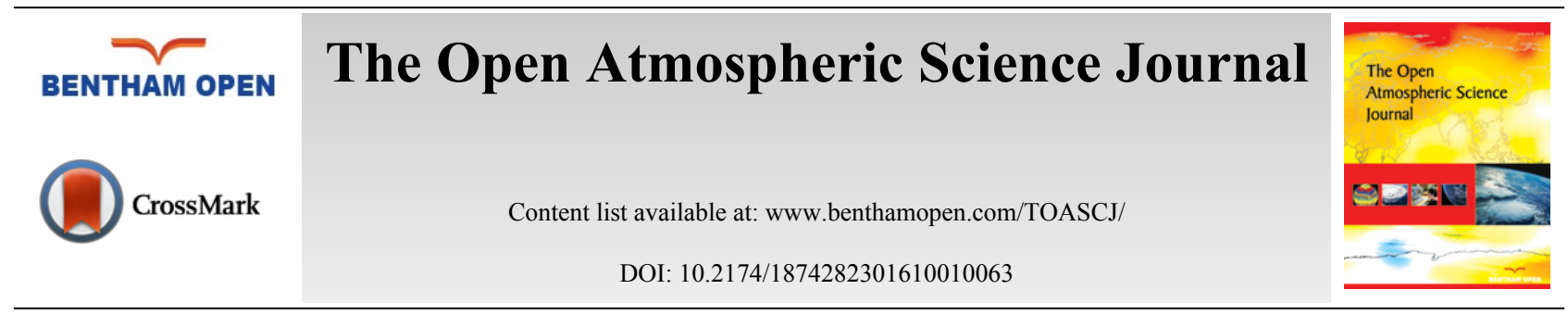

RESEARCH ARTICLE

\title{
Region-wise Effects of Climate Sensitive Variables on Some Specific Disease Burdens in Nepal
}

\author{
Srijan Lal Shrestha ${ }^{1, *}$, Iswori Lal Shrestha ${ }^{2}$ and Niraj Shrestha ${ }^{3}$ \\ ${ }^{\text {I} C e n t r a l ~ D e p a r t m e n t ~ o f ~ S t a t i s t i c s, ~ T r i b h u v a n ~ U n i v e r s i t y, ~ K i r t i p u r, ~ K a t h m a n d u, ~ N e p a l ~}$ \\ ${ }^{2}$ Nepal Environmental and Scientific Services, Kathmandu, Nepal \\ ${ }^{3}$ Nepal Medical College and Teaching Hospital, Jorpati, Kathmandu, Nepal
}

\begin{abstract}
:
Background:

In the context of climate change scenario in Nepal with rise in average surface air temperature, an ecological time series study has been conducted to examine and assess the effect of climate related variables on some specific disease burdens covering areas of all the eco-belts of Nepal.
\end{abstract}

\section{Objective:}

The study is conducted to examine several health effects associated with climate sensitive variables separately between the three ecobelts of Nepal and estimate environmental burden of diseases that can be attributed to temperature as the main climate variable.

\section{Method:}

The study is based upon daily meteorological data including temperature, rainfall, relative humidity and wind speed collected from the Department of Hydrology and Meteorology, Kathmandu and hospitalizations including water-borne (enteric fever, diahrreoal diseases and hepatitis), vector-borne (malaria, dengue, encephalitis, leishmaniasis and filarisis), urinary system (chronic kidney diseases, urinary tract infections and renal failure) and heart diseases (ischemic heart disease including angina pectoris, cardiovascular arrest, cardiac failures and other cardiovascular diseases) and mortality (all cause and diseases specific) are collected from the leading hospitals of the study area for 5 years in between 14 April 2009 and 13 April 2014.

\section{Results:}

Results of generalized linear modelling accounting distributed lag effects showed varied health effects between eco-belts and hospitalization/death types such as $2.1 \%$ to $7.3 \%$ rise in the considered hospitalizations per $1{ }^{\circ} \mathrm{C}$ rise in temperature, $0.9 \%$ to $8.2 \%$ rise in all cause deaths per $1{ }^{\circ} \mathrm{C}$ change in temperature below or above $20^{\circ} \mathrm{C},-8.7 \%$ to $2.4 \%$ change in hospitalizations/deaths per 1 $\mathrm{mm}$ rise in rainfall, $-1.6 \%$ to $7.3 \%$ change in hospitalizations/deaths per $1 \%$ rise in relative humidity and $-23.6 \%$ to $35 \%$ change in hospitalization/deaths per $1 \mathrm{~m} / \mathrm{s}$ rise in wind speed which can be attributed to many significant differences that prevail between the eco-belts of Nepal.

\section{Conclusion:}

Even though health effects are due to many factors, climate conditions are significant factors in affecting health of people and climate change is bound to affect the health burden of Nepalese people for which Nepal needs suitable preparedness and adaptation policies to counter and minimize the hazards of climate change in years to come.

Keywords: Attributable burden, Attributable fraction, Climate change, Distributed lag effects, Environmental burden of diseases, Statistical modelling.

\footnotetext{
* Address correspondence to this author at the Central Department of Statistics, Tribhuvan University, Kirtipur, Kathmandu, Nepal; Tel: 977-1-5539397; E-mails: srijan_shrestha@yahoo.com, srijan.lal.shrestha@gmail.com
} 


\section{INTRODUCTION}

Scientific studies in the recent past have revealed climate change with increase in global average surface temperature and changes in nature, intensity and frequency of precipitation $[1,2]$ which has resulted in global warming, gradual melting of snow and icebergs, rise in sea levels, increased evidences of floods, landslides, drought and desertification, etc. Studies in Nepal have also found increase in temperature and shifts in rainfall pattern [3 - 6]. According to a report published by the Department of Hydrology Meteorology in 2007, an increase of around $2^{\circ} \mathrm{C}$ temperature is projected for the period 2039-2069 compared to 1961-1990 based upon Regional Climate Model (RegCM3) which implies an average increase of $0.25^{\circ} \mathrm{C}$ per decade [7]. Similarly, World Bank Climate Change Knowledge Portal has projected an average increase of around $0.2^{\circ} \mathrm{C}$ average temperature per decade in the span of around 30 years in Nepal [8]. Other studies have indicated that from 1977-1994, mean annual maximum temperature in Nepal increased by $0.06^{\circ} \mathrm{C}$ and average temperature rise is estimated at $0.5^{\circ} \mathrm{C}$ per decade $[4,5]$. Precipitation is also becoming unpredictable and more erratic than ever, with more droughts and shorter periods of heavy rainfall [6]. Several regions in the country are already vulnerable to unevenly distributed and erratic weather [3]. These noticeable changes in climatic variables are certain to affect the public health concerns of Nepalese people. Many studies have been conducted concerning this issue of climate change and health burden in Nepal [3, 9 - 12].

A study conducted in Nepal covering all the three ecological regions and based upon annual data of 26 years (1982-2007) showed mixed results regarding occurrence of the number of incidence of malaria and diarrhoeal diseases with observed rainfall and temperature differences. The study attempted to relate between climate changes and occurrences of climate sensitive diseases but without obtaining health effect coefficients [9]. The Capacity Strengthening in the Least Developing Countries (CLACC) working paper on climate change and health in Nepal has reported that global climate change has serious implications for Nepal. The report mentioned that temperature has risen in Nepal and expected to continue to rise in the coming years partly due to increases in the human population, vehicles, development activities, and change in agricultural patterns. Vector and water-borne diseases have been found to be increasing within the country, along with a strong identified relationship between these diseases and temperature and precipitation [11].

Many studies have been conducted in various parts of the world in order to establish linkages between climate sensitive variables with hospital morbidities and mortality. A study conducted in London investigated the relation between heat and mortality in London and determined the temperature threshold at which death rates increase and quantified the effect of extreme temperatures on mortality based upon 21 years of daily data [13]. A study conducted in Vietnam to study the relationship between temperature and cardiovascular hospital admission showed that cardiovascular disease (CVD) admission was associated with both lower and higher temperatures compared to $26^{\circ} \mathrm{C}$ with the cumulative effect of cold exposure on CVD admissions was statistically significant with a relative risk of 1.12 (95\% CI: $1.01-1.25$ ) for $1{ }^{\circ} \mathrm{C}$ decrease below the threshold. The cumulative effect of hot temperature on CVD admissions was found to be non-significant and was estimated to be at a relative risk of 1.17 (95\% CI: $0.90-1.52)$ for $1^{\circ} \mathrm{C}$ increase in the temperature [14]. Association between ambient temperature and cardiovascular morbidity was also studied in Hong Kong based upon time series data of seven years. The study found that compared with $23.0^{\circ} \mathrm{C}$, the cumulative relative risk of emergency CVD hospitalization was 1.69 (95\% CI, 1.56-1.82) for extreme cold (first percentile) and $1.22(95 \% \mathrm{Cl}, 1.15-1.29)$ for moderate cold temperature (10th percentile) [15]. Another study reviewed the impacts of climate change on human health in South China which highlighted that the daily mean surface air temperatures above or below $26.4^{\circ} \mathrm{C}$ increases the death risk of the people in Guangzhou, China especially the elderly are vulnerable to variations in temperature [16]. A study attempted to develop health risk-based metrics for defining a heat-wave in Brisbane, Australia based upon Poisson generalized additive model to assess the impact of heat-waves on mortality and emergency hospital admissions (EHAs) in Brisbane. Results showed that the higher the intensity and the longer the duration of a heat-wave, the greater the health impacts [17].

A research article mentioned about various diseases associated with climate such as heat related deaths, cardiopulmonary diseases, vector-borne and water-borne diseases, malnutrition by droughts, etc and stresses the need of more researches in this area to reduce the potential impact of climate change on public health burden including more refined methods of quantitative risk assessment [18]. Similarly, another research article mentioned about several health impacts of climate change and mortality associated with temperature extremes, incidence of deaths and injuries with rainfall, dengue with temperature and rainfall and diarrheal diseases with rainfall [19]. Other studies showed risks of hospitalization for fluid and electrolyte disorders, renal failure, urinary tract infection, septicemia, and heat stroke were 
statistically and significantly higher on heat-wave days relative to matched non-heat wave days. Risks were generally highest on the heat-wave day but remained elevated for up to 5 subsequent days [20]; Checkley and colleagues used time series regression techniques to analyze the health effects of the 1997-98 EL Niño event on hospital admissions for diarrhea and revealed that for each $1{ }^{\circ} \mathrm{C}$ increase in temperature, hospital admission increased by $8 \%$ [21]; Singh et al. (2001) [22] used monthly data and showed that diarrhea notifications increased by approximately $3 \%$ per $1{ }^{\circ} \mathrm{C}$ increase in temperature; Raju et al. (2014) [23] linked higher occurrence of chronic kidney diseases (CKD) in warmer months (March-May); Hansen et al. (2008) [24] showed that admissions for renal disease and acute renal failure increased during heat-waves compared with non-heat wave periods with an incidence rate ratio of 1.100 (95\% CI: 1.003-1.206) and 1.255 (95\% CI 1.037-1.519), respectively.

In Nepal, studies based upon daily time series data to establish linkages between climate sensitive variables and health burden are lacking. Moreover, in view of existence of significant variations between ecological belts in Nepal emphasizes the need to account health effects separately between these regions in Nepal and explore how health effect coefficients, relative risks, attributable factors and attributable burdens differ between the regions. Literature review of the studies conducted at other parts of the world also showed variations in health effects due to meteorological parameters which suggests the need of further studies in this area. Consequently, the present study is carried out to link climate sensitive disease burdens and weather related variables through statistical modeling of daily changes in health burden data and corresponding changes in climate sensitive parameters like temperature, rainfall, humidity and wind speed and estimate the environmental burden of diseases that can be attributed to temperature as the main climate variable assessed separately between the eco-belts of Nepal.

\section{MATERIALS AND METHODS}

\subsection{Study Area}

The study covers 10 districts from all the three ecological belts of Nepal (Fig. 1). These are Dolakha from Mountain; Kathmandu, Lalitpur, Bhaktapur, Kavrepalanchowk and Dhankuta from Hill; and Chitwan, Sunsari, Morang and Jhapa from Terai. According to population census 2011, the percent population coverage from the selected districts is around $23.8 \%$ of the total population of Nepal of which $0.6 \%$ is from Mountain, $11.4 \%$ from Hill and $11.8 \%$ from Terai. Similarly, the percent household coverage is around $27.1 \%$ of the total households of Nepal of which $0.8 \%$ is from Mountain, $13.5 \%$ from Hill and $12.8 \%$ from Terai.

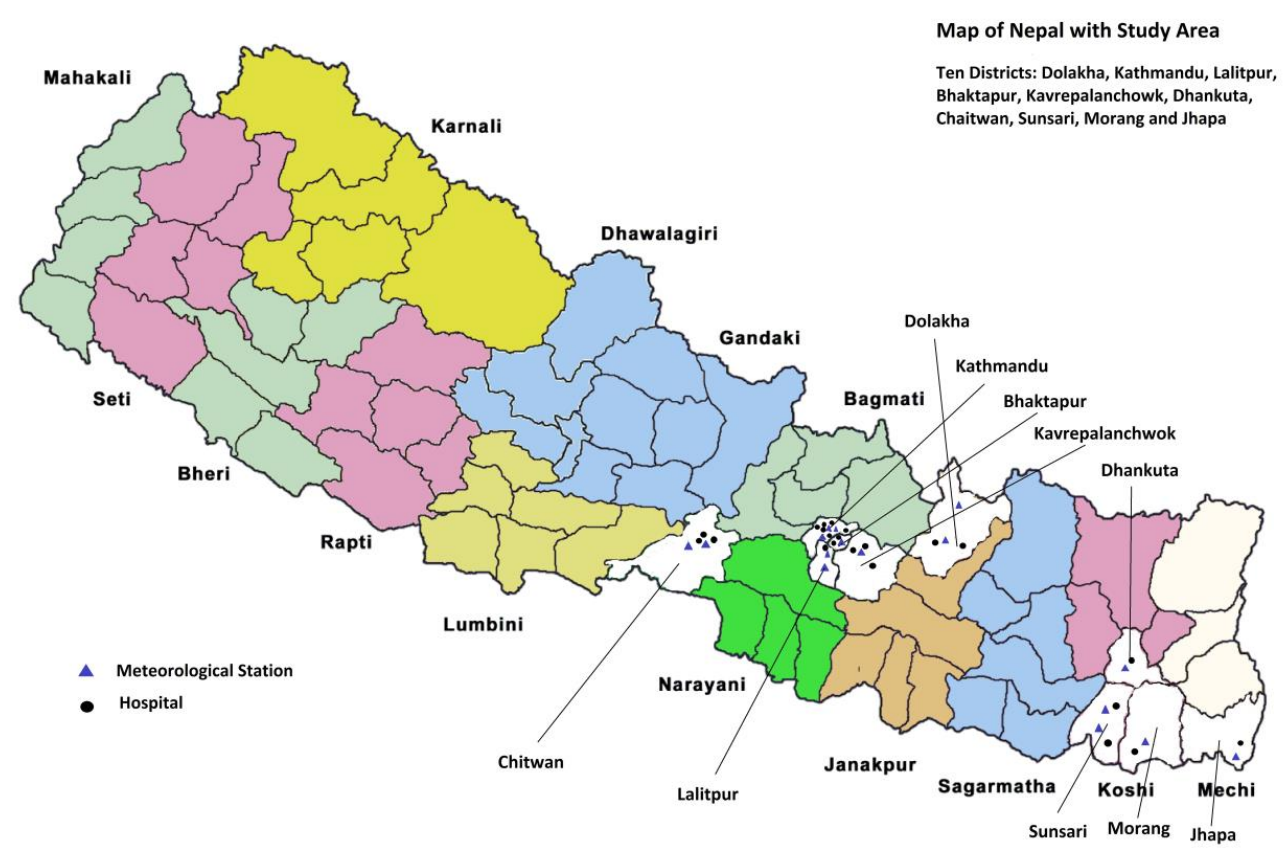

Fig. (1). Map of Nepal with selected districts, hospitals and meteorological stations. 


\subsection{Basic Steps and Data}

Environmental burden of disease (EBD) is a measure of the disease burden that can be attributed to an environmental risk factor. The basic methodology for the development of health effect coefficients and then estimation of environmental burden of diseases (EBD) is based upon ecological time series modeling of health and weather related data and application of the methodology developed by WHO for assessing the EBD that can be attributed to climate change $[25,26]$. In order to fulfill the objective of linking health burdens assessed by hospital morbidity and mortality with climate sensitive variables, the following three major steps were adopted as mentioned in WHO methodology [26].

I) Data collection of meteorological parameters and hospital inpatients/deaths.

II) Exposure - response modelling.

III) Estimation of EBD attributable to main climate sensitive variable.

\subsubsection{Data Collection}

Data are collected for health burden and climate sensitive variables as detailed below.

\subsubsection{Weather Data}

Climate sensitive variables considered for modeling are meteorological parameters namely temperature, rainfall, humidity and wind speed. Observed daily data of these parameters were collected for 2009-2014 from 16 meteorological stations located within the districts covered for the study which included 2 from Mountain, 8 from Hill and remaining 6 from Terai. In each station 6 meteorological variables (maximum and minimum temperatures, relative humidity at two different times daily, rainfall and wind) were collected for 6 years comprised of around 200,000 data points. From these meteorological variables 4 independent weather variables are formed for modeling. These are average temperature (average of minimum and maximum temperatures of a particular day), relative humidity (average of relative humidity measured two times daily), rainfall and wind speed. The source of these data is the Department of Hydrology and Meteorology (DHM), Kathmandu.

\subsubsection{Health Burden Data}

For building exposure-response models, data on health effects assumed to be linked with climate change were collected from the leading hospitals of the study area including government hospitals, teaching hospitals and some private hospitals of the study area. Altogether 22 hospitals were referred from the selected districts which included 2 hospitals from mountain region, 13 hospitals from hill and 7 hospitals from terai. Daily data from hospital admission and death records were collected for the reference period of 5 years collected according to Nepalese calendar starting from the first of Baishak 2066 BS (14 April 2009) till the end of Chaitra, 2070 BS (13 April 2014). Morbidity and mortality data were collected for water-borne (WB), vector-borne (VB), heart and urinary system diseases and also all cause mortality. WB diseases addressed are enteric fever, diarrheol diseases including gastroenteritis/diarrhea, cholera, dysentery and hepatitis (A \& E). VB diseases include malaria, dengue, encephalitis, leishmaniasis and filarisis. Heart diseases (HD) include mainly ischemic heart disease (including angina pectoris), cardiovascular arrest (CVA), cardiac failures and other cardiovascular diseases. Similarly, urinary system diseases include chronic kidney diseases (CKD), urinary tract infections (UTI) and renal failure. Mortality include all cause mortality and disease specific mortality of the above diseases. Total disease burden for Nepal were collected from the annual reports of Department of Health Services. Inpatient records from 22 referred hospitals showed around 50000 hospitalizations of the concerned diseases for the study period and around 10000 all cause deaths and 435 water-borne and vector-borne disease deaths.

\subsubsection{Confounding Variables}

Confounding variables are very essential to be addressed while modeling a dependent (or response) variable on predictor (or independent) variable(s) since if such variables are not addressed then the actual extent of effects due to independent variable(s) on the response variable would not be found and the results would be misleading. Moreover, it is not only the exposure variables like weather related variables that can affect health of people in time series modeling between climatic factors and health effects but there exist other factors also such as seasonal effects, holiday effect (Saturday) and trend effect since these variables changes along with observed health effects. Moreover, seasonal dummies are considered to analyze the effects due to seasonal changes on hospitalization/death, day of week categorical variable is considered to account holiday effect since Saturday is a public holiday in Nepal and secular trend is 
considered to address the trend effect on a response variable, if present. It is to be noted that public holidays are normally associated with reduced risks of health effects like hospitalization compared to working days. This may be due to various regions. For instance, a holiday may decrease the possibility of infection due to reduced exposures including environmental exposures and staying in relatively safe environment. People may be more relaxed and relatively tension free during holidays which can reduce the chances of hospitalization associated with HDs and risk of mortality associated with heart failures. Even in relatively risky meteorological conditions people in holidays could be relatively safer compared to working days. Consequently, it is important to include the variable in modeling health effects and climate variables particularly in a daily time series study.

\subsubsection{Exposure-response Modelling}

For exposure response modeling generalized linear model (GLM) with log link function (Poisson model) is used since it is an appropriate choice to account count dependent variable whose probability density function follows exponential family of distributions. The model or similar types of modeling techniques have been used in many similar studies [14, 17, 22, 24, 27] Moreover, time series models have distinct advantage over cross-sectional models since individual cofactors like socio-economic conditions, nutrition, behavior and other potential confounding factors used in cross-sectional studies are unlikely to be confounders in these models since they are not generally associated with day to day basis along with daily changes in weather related variables. The potential confounders are usually the variables that vary with time such as seasonal and trend variables.

\subsubsection{Statistical Model}

The generalized linear model with log link function can be expressed as follows. The model has count as the dependent variable with one or more predictor variables.

$$
y_{i}=e^{\beta_{0}+\beta_{1} x_{1 i}+\beta_{2} x_{2 i}+\ldots+\beta_{p} x_{p i}}+\varepsilon_{i}
$$

where $y_{i}$ is the observed value of the dependent variable (hospitalizations or deaths) for $i^{\text {th }}$ day and; $\beta_{k}$ is the $k^{\text {th }}(k=1$, $2, \ldots, p)$ parameter to be estimated which include weather variables and confounders namely trend component, day of week and seasonal dummies (only statistically significant $p$-value $\leq 0.1$ or just above were incorporated) ; $x_{k l}$ is the observed value for the $k^{\text {th }}$ independent variable like temperature or humidity or rainfall, etc. measured on the $i^{\text {th }}$ day; $\varepsilon_{i}$ is the stochastic error term of the model associated with the $i^{\text {th }}$ day . Different forms of lags were considered initially and the one which yielded higher statistical significance was finally chosen. The model can also be expressed as:

$$
\operatorname{Ln}\left(\mu_{i}\right)=\beta_{0}+\beta_{1} x_{1 i}+\beta_{2} x_{2 i}+\ldots .+\beta_{p} x_{p i}=\beta_{\sim}^{t} x
$$

where $\underset{\sim}{\beta}$ is the vector of unknown parameters and $\underset{\sim}{x}$ is the vector of independent variables including a unity for the intercept, $\beta_{0}, E\left(y_{i}\right)=\mu_{i}$ and has the natural logarithm as the link function. The predictors include meteorological parameters, seasonal dummy variables, day of week (Saturday) as a categorical variable and an annual trend variable. A seasonal dummy is coded as 0 if a day belongs the season or 1 otherwise. For instance, Summer is coded as 0 if a day belongs to the season otherwise coded as 1 . Similarly, Saturday is coded as 0 and other days are coded as 1 . Trend value takes the value $1,2, . ., 5$ for 5 consecutive years starting from $2066 \mathrm{BS}$. The model is suitable to link hospital admissions (or mortality count) with weather related variables as mentioned above. Moreover, meteorological variables are reconstructed using the lag structures considered for statistical modeling for different lag periods that ranged from same day to several weeks. Estimate of relative risk per unit increase in the $j^{\text {th }}$ risk factor (independent variable) is calculated as:

$$
\operatorname{Est} .\left(R R_{j}\right)=e^{\hat{\beta}_{j}}
$$

The corresponding estimate of percent change in health effect is given by:

$$
\left(\text { Est.RR }_{j}-1\right) \times 100
$$

The estimate is applicable for values within the threshold values of meteorological parameters where health effects are assumed to exist and not far away from the observed meteorological conditions. Details regarding the threshold 
values are explained below in this section. In Equation $3, \hat{\beta}_{j}$ is the maximum likelihood estimate of $\beta_{j}$ computed using the method of iteratively reweighted least squares in generalized linear model [28]. Estimates are obtained using the statistical package for the social sciences (SPSS) software, version 20.

Altogether 14 generalized linear models are built. The response variables are WB disease hospitalization, VB disease hospitalization, urinary system disease hospitalization, HD hospitalization, all cause mortality and WB \& VB disease deaths. From Mountain, only 2 models with WB disease hospitalization and all cause deaths are built due to very low (or zero) hospitalizations in other health effects from the selected 2 hospitals. From Hill and Mountain models are built for all the 6 considered health effects resulting in 14 models. Regarding meteorological variables, data from all the considered parameters were taken from all the ecological regions. Models are built independently for eco-belts and responses covering the district (s), hospitals, and meteorological stations referred within an eco-belt through taking daily averages of meteorological parameters except in the case of rainfall for which totals are taken instead. Daily totals of health responses from different hospitals are considered for each eco-belt for the entire analysis period of 5 years. The information regarding area, population, hospital and meteorological station coverage is shown in the Table $\mathbf{1}$.

Table 1. Information on study coverage.

\begin{tabular}{|l|c|c|c|c|}
\hline Coverage & Mountain & Hill & Terai & Total \\
\hline Area (District) & 1 & 5 & 4 & 10 \\
\hline Population (\% of Population of Nepal) & 0.6 & 11.4 & 11.8 & 23.8 \\
\hline Hospital & 2 & 13 & 7 & 22 \\
\hline Meteorological Station & 2 & 8 & 6 & 16 \\
\hline Models & 2 & 6 & 6 & 14 \\
\hline
\end{tabular}

The models corresponding specific eco-belts and health responses are shown in Table 2.

Table 2. Model description.

\begin{tabular}{|c|c|c|c|c|c|}
\hline Model & Eco-belt & Health Response & Model & Eco-belt & Health Response \\
\hline 1 & Mountain & WB hospitalization & 8 & Hill & All cause death \\
\hline 2 & Mountain & All cause death & 9 & Terai & WB hospitalization \\
\hline 3 & Hill & WB hospitalization & 10 & Terai & VB hospitalization \\
\hline 4 & Hill & VB hospitalization & 11 & Terai & Urinary system hospitalization \\
\hline 5 & Hill & Urinary system hospitalization & 12 & Terai & WB and VB death \\
\hline 6 & Hill & WB and VB death & 13 & Terai & HD hospitalization \\
\hline 7 & Hill & HD hospitalization & 14 & Terai & All cause death \\
\hline
\end{tabular}

\subsubsection{Lag Effects}

It is logical to assume that health effects on a particular day can depend not only the weather condition of the same day but may have resulted due to weather conditions of previous days as well. Moreover, consideration of lag effects is necessary while modeling health effects based upon daily time series data as shown by other daily time series studies $[29,30]$. For the purpose, several lag structures are considered namely moving average (MA), geometric decay and arithmetic decay. Another aspect while considering lag effects is the choice of suitable lag length. For the purpose, several extended lag effects are considered and the length which suites the best regarding extent of effects and statistical significance is finally chosen. Additionally, incubation periods of bacteria/viruses that causes WB and VB diseases are noted in order to choose the lag lengths for statistical modeling. It is noted that incubation period ranges between 0.5 to 14 days (excluding hepatitis) for WB diseases whereas the period ranges between few days to months/years for vectorborne diseases [31 - 35].

\subsubsection{Lag Structures}

Several suitable lag structures were explored namely geometric (exponential) decay, arithmetic decay and moving averages. The mathematical models for lag structures are as follows. The model used for geometric decay is:

$$
w_{i}=w_{0} \lambda(1-\lambda)^{i}
$$


where $w_{i}$ is the assigned weight for $i^{\text {th }}$ lag, $w_{0}$ is a constant related to the total weight for all lags and $\lambda$ is the rate of decay. Similarly, the model for arithmetic decay is:

$$
w_{i}=w_{0} \lambda(k+1-i)
$$

where $k$ represents the total number of lags including same day lag and $w_{0}=\frac{1}{(k+1)(k+2)}[29,30]$.

Lag weights depend upon the functional form of the lag structure and the lag length. In the analysis different lag lengths are considered which resulted in different sets of lag weights for arithmetic and geometric decay lag structures. A typical graph of lag weights used for geometric decay lag structure is shown in Fig. (2). It is constructed for $w_{0}=$ 0.9832 and $\lambda=0.40$.

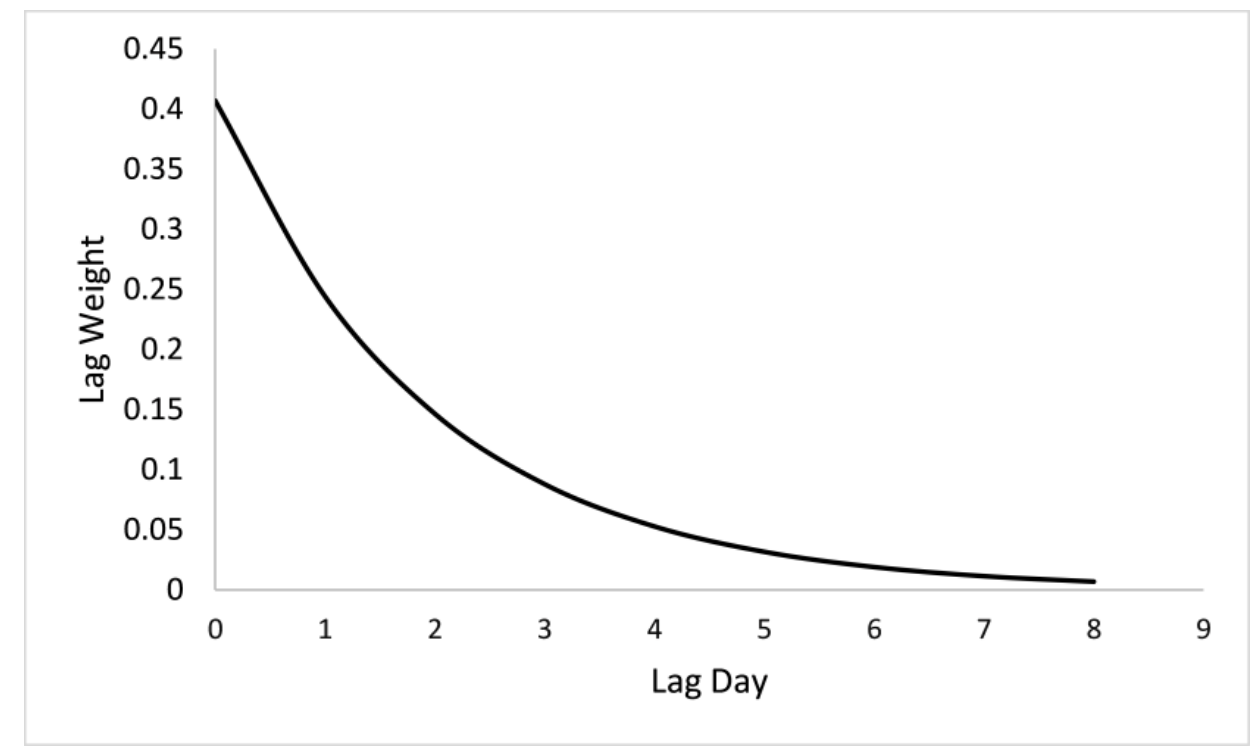

Fig. (2). Geometric decay of lag weights.

\subsubsection{Estimation of EBD Attributable to Average Temperature as the Main Climatic Variable}

The basic approach for estimating the environmental burden of diseases is common to every environmental risk factor. Computation of attributable fraction (AF) is done by standard methodology as mentioned in WHO literatures and computed for total mortality and morbidities as follows [36].

$$
A F_{m}=\frac{\sum_{n=1}^{r} P_{m n} R R_{m n}-1}{\sum_{n=1}^{r} P_{m n} R R_{m n}}
$$

where $A F_{m}$ is the attributable fraction (also called the impact fraction) for $m^{\text {th }}$ model $(m=1,2, \ldots, 14) ; P_{m n}$ is the proportion of days in $n^{\text {th }}(n=1,2, . ., r)$ categorized group of climatic condition out of the total number of days calculated for the $m^{\text {th }}$ model; $R R_{m n}$ is the relative risk at exposure category $n$ compared to the reference level or threshold value of 0 $-10^{\circ} \mathrm{C}$ minimum temperature depending upon the response variable calculated for the $m^{\text {th }}$ model. The total disease burden for EBD assessment is based upon available annual morbidity and mortality data of 17 years collected from the Department of Health Services (DoHS) Annual Reports. For EBD attribution, total morbidity including outpatient morbidity are also taken into account assuming that health effect coefficients and relative risks modeled from inpatient data would not be much different if similar models are built using outpatient data. The attributable burden for the $m^{\text {th }}$ model is as follows. 


$$
A B_{m}=A F_{m} \times T B_{m}
$$

where $T B_{m}$ is the total burden in the $m^{\text {th }}$ model.

\subsubsection{Threshold Values for Computing Relative Risks}

The threshold values of temperature for computation of attributable fractions are based upon the finding of the studies as mentioned below and also upon the observed frequency curve of hospitalizations at different temperatures. Studies have been conducted to examine about weather variables and survival and development of bacteria/parasites/viruses and their carriers. Studies have shown that a pathogen needs a certain temperature range to survive and develop. For instance, a study showed that a minimum temperature of $25-26^{\circ} \mathrm{C}$ is required for the transmission of Japanese Encephalitis Virus (JEV) [37]. The development of malaria parasite (Plasmodium falciparum and Plasmodium vivax) ceases when temperature exceeds $33^{\circ}-39^{\circ} \mathrm{C}$ [38]. Reproduction of Salmonella increase as temperature rises in the range between $7^{\circ} \mathrm{C}$ and $37^{\circ} \mathrm{C}$ [39]. Similarly, since the falciparum malaria mostly exists when temperature is above $16^{\circ} \mathrm{C}$, a temperature dropping to below this threshold will benefit malaria control [40]. The detailed review of publications regarding climate change and human infectious diseases including temperature threshold values published during the period 1990-2015 has been done by Xiaoxu Wu et al. [41]. Additionally, in the present study, the hospitalization frequency-temperature curves showed around 100 cases of water-borne hospitalization $(<1 \%)$ between $5-10^{\circ} \mathrm{C}$, only around 10 cases of vector-borne $(<1 \%)$ and renal disease hospitalizations $(<1 \%)$ below $10^{\circ} \mathrm{C}$. Based upon the review and findings, the threshold values of minimum average temperature considered for water-borne, vector-borne and renal disease are chosen as $5^{\circ} \mathrm{C}, 10^{\circ} \mathrm{C}$ and $10^{\circ} \mathrm{C}$, respectively. It is to be noted that relative risks are computed for different climate conditions which have higher risks compared to the reference level below or at the level the health risks are assumed more or less non-existent for EBD calculations. The upper threshold values are not mentioned since it is not reasonable to assume that the maximum average temperatures for any day considered in data modeling can be taken as risk free days from the considered hospitalizations or deaths regarding the climatic condition aggregates.

\section{RESULTS}

Several statistical models are developed ecobelt-wise in order to link and assess health effects with climate sensitive variables and confounding variables in order to examine the differences in health effect coefficients between these regions. Altogether, 14 models are developed, two from Mountain and six each from Terai and Hill accounting waterborne, vector-borne, heart disease, urinary system disease hospitalizations and all cause and disease specific deaths. Health effect coefficients are discussed and compared separately for different meteorological parameters and ecological belts. The effects are presented as percent change in hospitalization/deaths per unit change in meteorological parameters such as $1^{\circ} \mathrm{C}$ rise in average temperature (except in HD hospitalization/all cause death response models) or $1^{\circ} \mathrm{C}$ change in average temperature below or above the overall average $\left(20^{\circ} \mathrm{C}\right.$ ) (only in HD hospitalization/all cause death response models), $1 \mathrm{~mm}$ increase in rainfall (all models), $1 \%$ rise in relative humidity (all models) and $1 \mathrm{~m} / \mathrm{s}$ rise in wind speed (all models) and computed from Equation 4 separately for different health effects and eco-belts. For all cause death and HD hospitalization, the percent rise in health effects due to temperature is computed differently as percent increase in health effects due to $1^{\circ} \mathrm{C}$ increase or decrease in temperature compared to $20^{\circ} \mathrm{C}$ since risk of these health effects are likely to increase with rising temperature difference compared to a normal or least risk condition which is taken as $20^{\circ} \mathrm{C}$ in this analysis.

Prior to building statistical models, a descriptive analysis is carried out by constructing line graphs consisting of 14 panels covering all the eco-belts and health responses to detect possible presence of associations between the main climate variable, temperature using monthly data and corresponding health responses as shown in Fig. (3). The line graphs showed noticeable increasing trends along with temperature for WB, VB and urinary system hospitalizations and WB \& VB and all cause deaths with substantial amounts of fluctuations. The figures indicate that even though there are strong evidences of association between temperature and health responses, the observed fluctuations of health responses suggest the presence of variables other than temperature affecting health responses. Moreover, substantial amounts of variations are also detected between the models built for different eco-belts which justifies the methodology of building models separately for different eco-belts. 


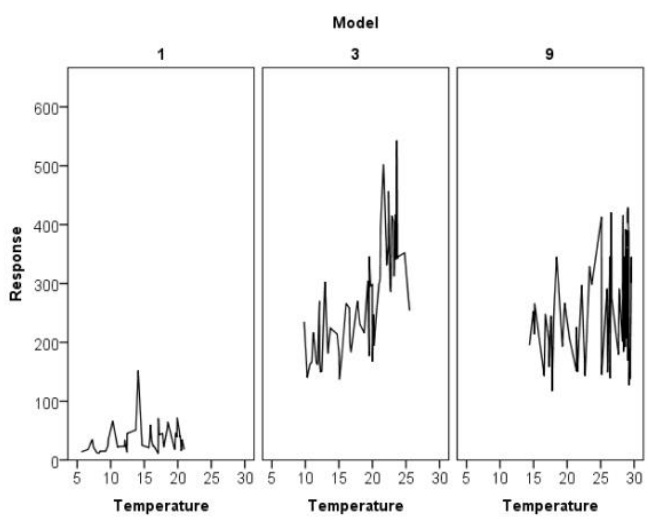

(a) Water-borne Hospitalizations

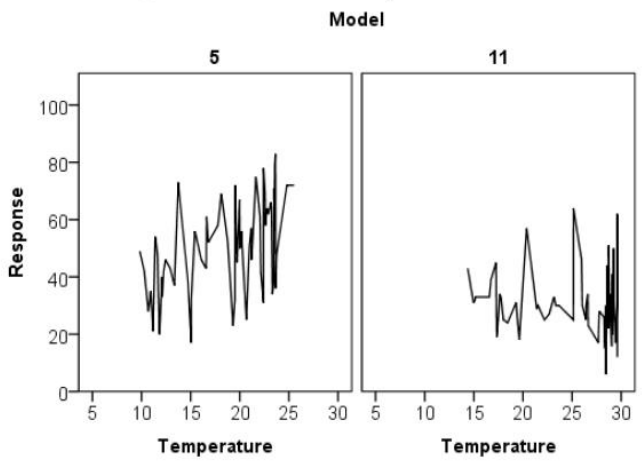

(c) Urinary System Hospitalization

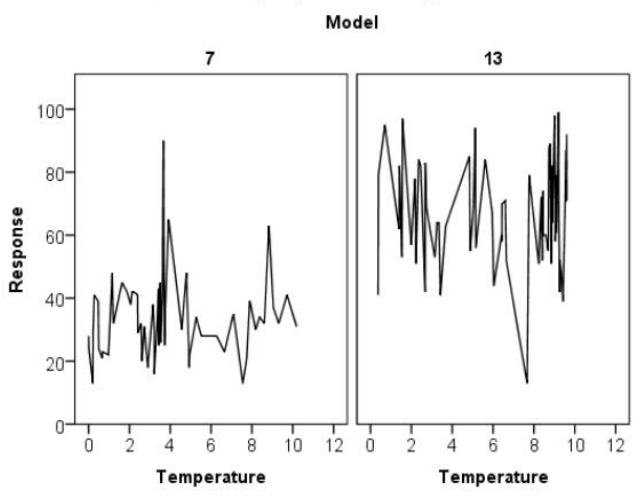

(e) HD Hospitalization

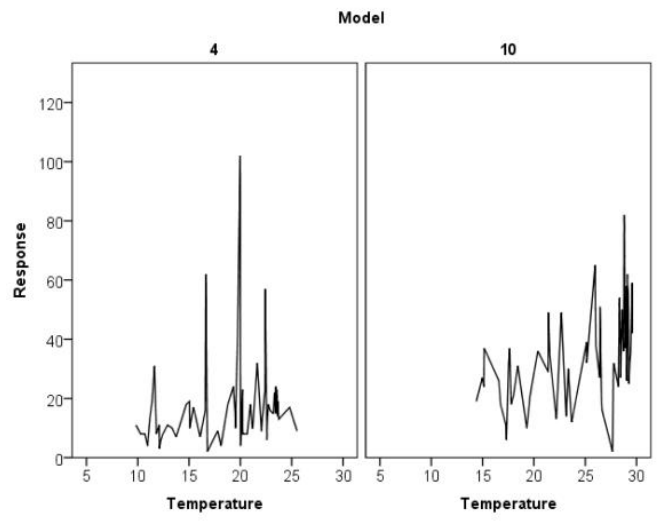

(b) Vector-borne Hospitalizations

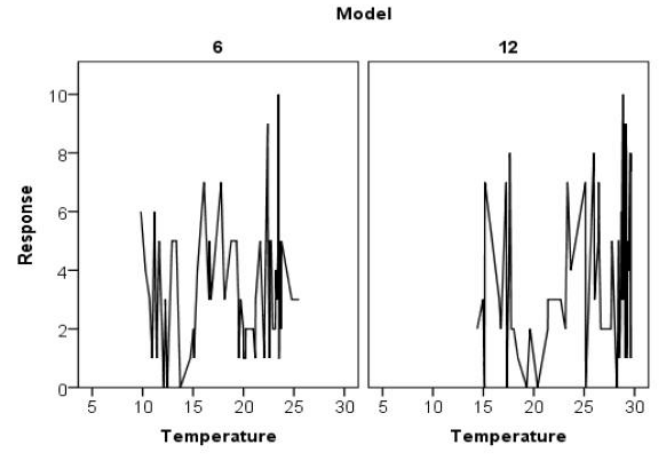

(d) WB \& VB Deaths

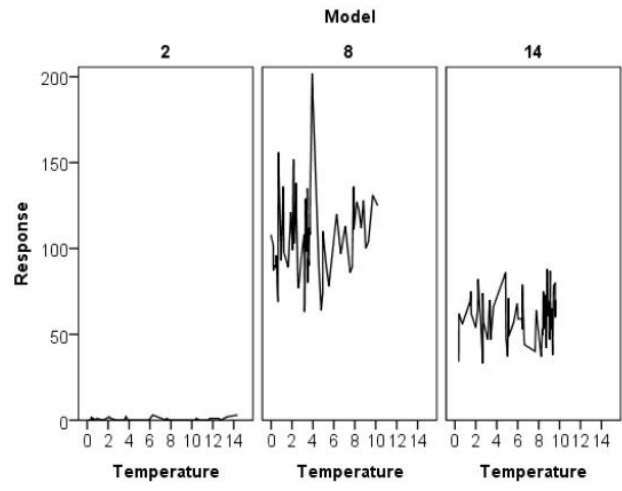

(f) All Cause Deaths

Fig. (3). Panel graphs of hospitalization and temperature time series.

Table 3. Percent rise in effects per $1^{\circ} \mathrm{C}$ rise in temperature.

\begin{tabular}{|l|c|c|c|c|}
\hline Health Effect & Particular & Mountain & Hill & Terai \\
\hline \multirow{3}{*}{ WB hospitalization } & Estimate & 5.2 & 5.4 & 2.1 \\
\cline { 2 - 5 } & $95 \% \mathrm{CI}$ & {$[3.4 ; 6.9]$} & {$[4.8 ; 5.9]$} & {$[1.5 ; 2.7]$} \\
\cline { 2 - 5 } & Lag & MA 15 & GEO 7 & GEO 7 \\
\hline \multirow{3}{*}{ VB hospitalization } & Estimate & - & 6.8 & 7.3 \\
\cline { 2 - 5 } & $95 \% \mathrm{CI}$ & - & {$[3.9 ; 9.7]$} & {$[5.9 ; 8.8]$} \\
\cline { 2 - 5 } & Lag & - & MA 45 & MA 30 \\
\hline \multirow{3}{*}{ Urinary system hospitalization } & Estimate & - & 3.2 & 2.4 \\
\cline { 2 - 5 } & $95 \% \mathrm{CI}$ & - & {$[1.4 ; 4.9]$} & {$[1.0 ; 3.9]$} \\
\cline { 2 - 5 } & Lag & - & GEO 7 & MA 21 \\
\hline
\end{tabular}


(Table $\square$ ) contd......

\begin{tabular}{|c|c|c|c|c|}
\hline Health Effect & Particular & Mountain & Hill & Terai \\
\hline \multirow{3}{*}{ HD hospitalization } & Estimate & 一 & 8.2 & 0.9 \\
\hline & $95 \% \mathrm{CI}$ & 一 & {$[4.4 ; 12.2]$} & {$[-0.3 ; 2.1]$} \\
\hline & Lag & 一 & GEO 7 & MA 21 \\
\hline \multirow{3}{*}{ All cause deaths } & Estimate & 8.2 & 2.8 & 0.9 \\
\hline & $95 \% \mathrm{CI}$ & {$[0.0 ; 17.1]$} & {$[1.3 ; 4.2]$} & {$[0.2 ; 1.6]$} \\
\hline & Lag & MA 1 & MA 3 & MA 30 \\
\hline \multirow{3}{*}{ WB \& VB deaths } & Estimate & 一 & 5.3 & 5.2 \\
\hline & $95 \% \mathrm{CI}$ & 一 & {$[0.3 ; 10.4]$} & {$[2.1 ; 8.3]$} \\
\hline & Lag & - & SAME DAY & MA 30 \\
\hline
\end{tabular}

— implies model not built; CI implies confidence interval.

\subsection{Effect of Temperature}

The health effects of rise in temperature on water-borne disease hospitalization is found largest in Hill with 5.4\% rise in the hospitalization, slightly lower in Mountain with $5.2 \%$ rise but substantially smaller in Terai with $2.1 \%$ rise in the hospitalization per $1{ }^{\circ} \mathrm{C}$ rise in average temperature. Similarly, the effect of rise in temperature on vector-borne disease hospitalization is relatively higher in Terai with $7.3 \%$ rise in the hospitalization per $1{ }^{\circ} \mathrm{C}$ rise in average temperature compared to $6.8 \%$ in Hill. Moreover, effects of rise in temperature in urinary system disease hospitalization and WB \& VB disease deaths are smaller in Terai (2.4\%-5.2\%) compared to Hill (3.2\%-5.3\%) though the differences are only marginal. If effects on all cause mortality are examined, it is seen that the effect is largest in Mountain with $8.2 \%$ increase but decreases substantially to $2.8 \%$ in Hill and $0.9 \%$ in Terai per $1{ }^{\circ} \mathrm{C}$ change in average temperature below or above $20^{\circ} \mathrm{C}$ which demonstrate that higher coldness and hotness increases the chances of deaths in all the ecobelts of Nepal. This also implies that the effect of extreme hotness/coldness is higher in Mountain and relatively smaller in Hill and smallest in Terai. Examination of effects on HD hospitalization also reveals that effect of absolute difference in temperature relative to $20^{\circ} \mathrm{C}$ is much higher in Hill (8.2\%) compared to Terai (0.9\%) (Table 3)(Fig. 4). Lag type and lag length show that most of the lags found appropriate are moving average (MA) and geometric decay (GEO). Lag lengths are found much higher for VB hospitalization (30-45 days) primarily because incubation period is higher compared to WB hospitalization (7-15 days) which is consistent with review of literature on incubation periods of WB and VB diseases. For other responses, lag length ranged widely from same day to 30 days. Additionally, lag length is found much higher in Terai compared to Hill regarding urinary system and HD hospitalizations and mortality.

\subsection{Effects of Rainfall}

Effects of rainfall are detected for WB, VB and urinary system disease hospitalizations and found statistically insignificant for rest of the responses at 10\% significance level. Analysis of effects of rainfall by eco-belts showed some contrasting results with negative coefficients in Mountain and Terai regions where relatively high rainfall is associated with relatively low WB hospitalizations. In Hill $2.4 \%$ rise in WB disease hospitalization is estimated per $1 \mathrm{~mm}$ rise in rainfall. However, analysis of Mountain and Terai regions actually suggests a different scenario with $0.6 \%$ and $2.3 \%$ decrease in WB hospitalizations in Terai and Mountain, respectively per $1 \mathrm{~mm}$ rise in rainfall (Table 4)(Fig. 5). Effects of rainfall on VB hospitalizations are also found negatively associated with varied effects in magnitude with $8.7 \%$ and $1.03 \%$ decrease in VB disease hospitalization in Hill and Terai, respectively per $1 \mathrm{~mm}$ rise in rainfall. Lastly, examination of effects on urinary system disease hospitalization showed negative association in Terai with $2.1 \%$ decrease in urinary system hospitalization but $1.2 \%$ increase in the same per $1 \mathrm{~mm}$ increase in rainfall in Hill. Additionally, analysis of data revealed insignificant associations between mortalities and rainfall. Lag type shows all of them following moving average (MA). Lag lengths are found to be much higher for VB hospitalization (21-45 days) as in temperature effect compared to WB hospitalization for which lag length is found to be consistent with 15 days. For other responses, lag length ranged widely from 15 to 21 days. 


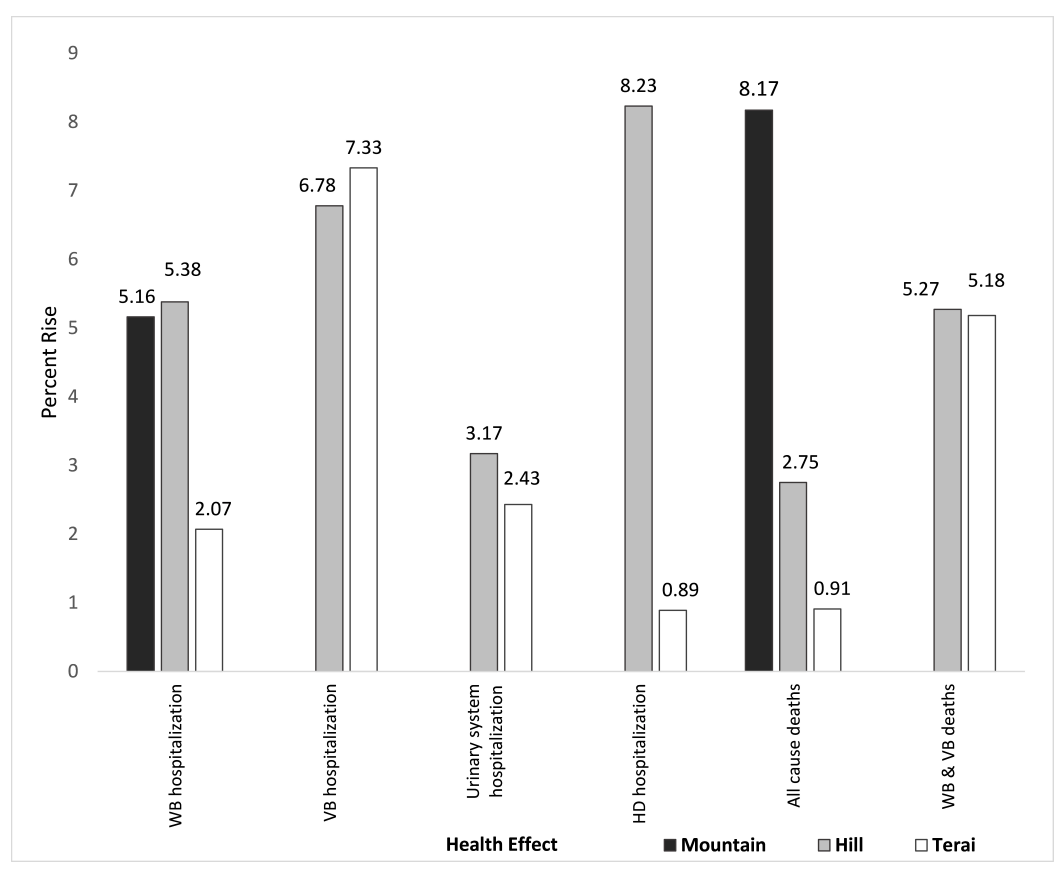

Fig. (4). Percent rise in effects per $1^{\circ} \mathrm{C}$ rise in temperature.

\subsection{Effect of Relative Humidity}

The effects of relative humidity showed increase in humidity increases the chances of VB, urinary system hospitalizations and HD hospitalization as well as all cause deaths but decreases the chances of WB hospitalization with magnitude of effects differing between eco-belts. Results indicate that humid air having more moisture content is favorable condition to vector-borne disease carriers whereas not favorable to water-borne diseases. Results demonstrate $1.6 \%$ and $0.6 \%$ decrease in WB hospitalization in Terai and Hill, respectively per $1 \%$ rise in relative humidity. However the effect is found insignificant in Mountain. The effect on VB is found substantially larger in Hill compared to Terai with $7.3 \%$ rise in VB hospitalization per $1 \%$ rise in relative humidity in Hill and $2.2 \%$ rise in the hospitalization in Terai. Urinary system hospitalization is also found increasing as humidity increases with $0.8 \%$ and $2.1 \%$ rise in the hospitalization in Hill and Terai, respectively. Estimates revealed that $1 \%$ rise in relative humidity is not associated with mortality in Hill whereas $0.7 \%$ rise in deaths is detected in Terai. Lastly, HD hospitalization is found to be associated with humidity in Terai only and WB \& VB deaths associated only in Hill with $0.4 \%$ and 3.2\% rise in the effects per $1 \%$ rise in relative humidity, respectively (Table 5)(Fig. 6). Lag type shows all of them following MA lag structure. Here also, lag lengths are found to be much higher for VB hospitalization (21-45 days) compared to WB hospitalization for which lag length is found to be consistent with 15 days. For other responses, lag length ranged widely from same day to 30 days.

Table 4. Percent change in effects per $1 \mathrm{~mm}$ rise in rainfall.

\begin{tabular}{|c|c|c|c|c|}
\hline Health Effect & Particular & Mountain & Hill & Terai \\
\hline \multirow[t]{2}{*}{ WB hospitalization } & Estimate & $\begin{array}{c}-2.3 \\
{[-3.2 ;-1.3]}\end{array}$ & $\begin{array}{c}2.4 \\
{[1.7-2.9]}\end{array}$ & $\begin{array}{c}-0.6 \\
{[-0.1 ;-0.2]}\end{array}$ \\
\hline & Lag & MA 15 & MA 15 & MA 15 \\
\hline \multirow[t]{2}{*}{ VB hospitalization } & Estimate & - & $\begin{array}{c}-8.7 \\
{[-11.3 ;-6.0]}\end{array}$ & $\begin{array}{c}-1.0 \\
{[-2.0 ;-0.1]}\end{array}$ \\
\hline & Lag & & MA 45 & MA 21 \\
\hline \multirow[t]{2}{*}{ Urinary system hospitalization } & Estimate & - & $\begin{array}{c}1.2 \\
{[-0.2 ; 2.7]}\end{array}$ & $\begin{array}{c}-2.1 \\
{[-3.2 ;-1.0]}\end{array}$ \\
\hline & Lag & & MA 15 & MA 21 \\
\hline \multirow[t]{2}{*}{ HD hospitalization } & Estimate & - & $\mathrm{X}$ & $\begin{array}{c}-0.9 \\
{[-1.7 ; 0.0]}\end{array}$ \\
\hline & Lag & & $\mathrm{X}$ & MA 21 \\
\hline
\end{tabular}

$\mathrm{X}$ implies not included in the model due to statistical insignificance. 
Table 5. Percent change in effects per $1 \%$ rise in relative humidity.

\begin{tabular}{|c|c|c|c|c|}
\hline Health Effect & Particular & Mountain & Hill & Terai \\
\hline \multirow{3}{*}{ WB hospitalization } & Estimate & $\mathrm{X}$ & -0.6 & -1.6 \\
\hline & $95 \% \mathrm{CI}$ & $\mathrm{X}$ & {$[-1.0 ;-0.2]$} & {$[-1.9 ;-1.3]$} \\
\hline & Lag & $\mathrm{X}$ & MA 15 & MA 15 \\
\hline \multirow{3}{*}{ VB hospitalization } & Estimate & - & 7.3 & 2.2 \\
\hline & $95 \% \mathrm{CI}$ & - & {$[5.1 ; 9.5]$} & {$[1.3 ; 2.9]$} \\
\hline & Lag & - & MA 45 & MA 21 \\
\hline \multirow{3}{*}{ Urinary system hospitalization } & Estimate & - & 0.8 & 2.1 \\
\hline & $95 \% \mathrm{CI}$ & - & {$[-0.1 ; 1.8]$} & {$[1.2 ; 2.9]$} \\
\hline & Lag & - & MA 15 & MA 21 \\
\hline \multirow{3}{*}{ HD hospitalization } & Estimate & - & $\mathrm{X}$ & 0.4 \\
\hline & $95 \% \mathrm{CI}$ & - & $\mathrm{X}$ & {$[-0.2 ; 1.0]$} \\
\hline & Lag & - & $\mathrm{X}$ & MA 21 \\
\hline \multirow{3}{*}{ All cause deaths } & Estimate & $\mathrm{X}$ & $\mathrm{X}$ & 0.7 \\
\hline & $95 \% \mathrm{CI}$ & $\mathrm{X}$ & $\mathrm{X}$ & {$[0.3 ; 1.1]$} \\
\hline & Lag & $\mathrm{X}$ & $\mathrm{X}$ & MA 30 \\
\hline \multirow{3}{*}{ WB \& VB deaths } & Estimate & - & 3.2 & $\mathrm{X}$ \\
\hline & $95 \% \mathrm{CI}$ & - & {$[1.0 ; 5.3]$} & $X$ \\
\hline & Lag & - & SAME DAY & $\mathrm{X}$ \\
\hline
\end{tabular}

$\mathrm{X}$ implies not included in the model due to statistical insignificance.

— implies model not built; CI implies confidence interval.

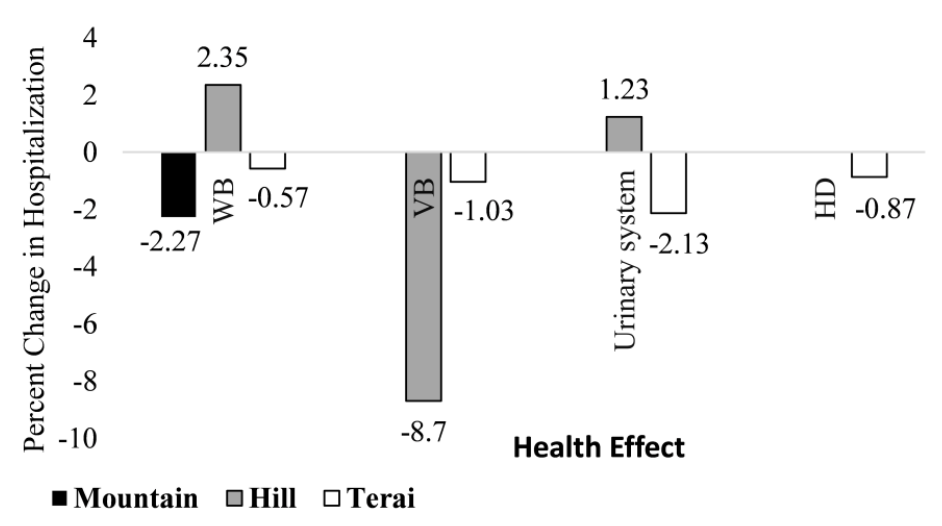

Fig. (5). Percent change in effects per $1 \mathrm{~mm}$ rise in rainfall.

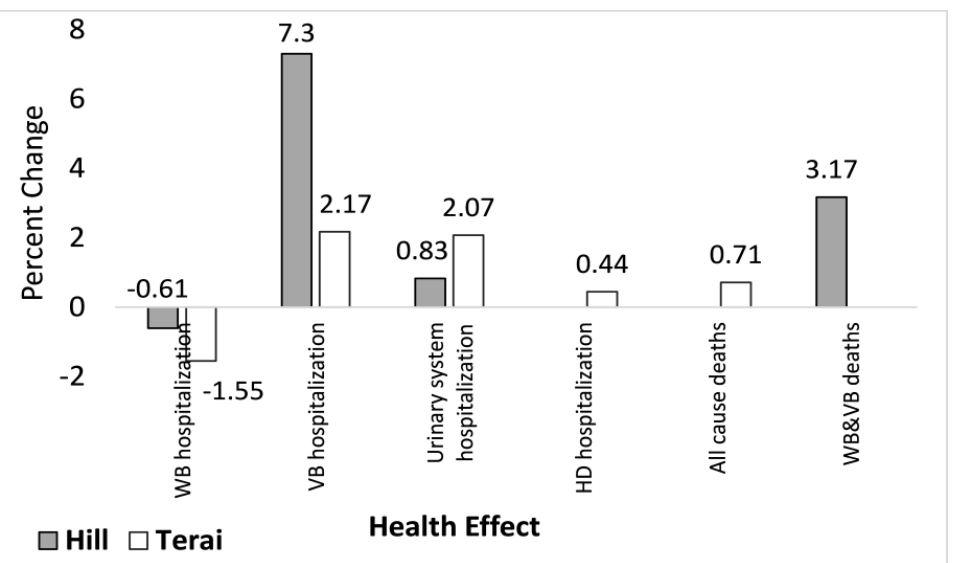

Fig. (6). Percent change in effects per $1 \%$ rise in relative humidity. 
Table 6. Percent change in effects per $1 \mathrm{~m} / \mathrm{s}$ increase in wind speed.

\begin{tabular}{|c|c|c|c|c|}
\hline Health Effect & Particular & Mountain & Hill & Terai \\
\hline \multirow{3}{*}{ WB hospitalization } & Estimate & -23.6 & $\mathrm{X}$ & $\mathrm{X}$ \\
\hline & $95 \% \mathrm{CI}$ & {$[-27.3 ;-19.7]$} & $\mathrm{X}$ & $\mathrm{X}$ \\
\hline & Lag & MA 15 & $\mathrm{X}$ & $\mathrm{X}$ \\
\hline \multirow{3}{*}{ VB hospitalization } & Estimate & - & 35.0 & 1.7 \\
\hline & $95 \% \mathrm{CI}$ & - & {$[7.4 ; 69.6]$} & {$[-0.5 ; 3.4]$} \\
\hline & Lag & - & MA 45 & MA 7 \\
\hline \multirow{3}{*}{ Urinary system hospitalization } & Estimate & - & 17.5 & -4.0 \\
\hline & $95 \% \mathrm{CI}$ & - & {$[5.0 ; 31.5]$} & {$[-6.9 ;-1.0]$} \\
\hline & Lag & - & MA 15 & MA 21 \\
\hline \multirow{3}{*}{ All cause deaths } & Estimate & $\mathrm{X}$ & -9.0 & $\mathrm{X}$ \\
\hline & $95 \% \mathrm{CI}$ & $\mathrm{X}$ & {$[-14.7 ;-2.9]$} & $\mathrm{X}$ \\
\hline & Lag & $\mathrm{X}$ & MA 7 & $\mathrm{X}$ \\
\hline \multirow{3}{*}{ WB \& VB deaths } & Estimate & - & $\mathrm{X}$ & -6.4 \\
\hline & $95 \% \mathrm{CI}$ & - & $\mathrm{X}$ & {$[-11.6 ;-0.9]$} \\
\hline & Lag & - & $\mathrm{X}$ & GEO 7 \\
\hline
\end{tabular}

$\mathrm{X}$ implies not included in the model due to statistical insignificance.

— implies model not built; CI implies confidence interval.

\subsection{Effect of Wind}

Examination of eco-belt-wise differences in wind effects revealed that Mountain region showed negative association with WB hospitalization but statistically insignificant association is detected in Hill and Terai regions with WB hospitalization. The effect of wind on VB disease hospitalization is found very high in Hill with around 35\% increase in the hospitalization per $1 \mathrm{~m} / \mathrm{s}$ increase in wind speed and comparatively very low in Terai with $1.7 \%$ rise in VB hospitalization. Similarly, contrasting effects are detected on urinary system disease hospitalization as well. Lastly, all cause deaths is found associated only in Hill with $9 \%$ decrease in the deaths per $1 \mathrm{~m} / \mathrm{s}$ increase in wind speed and WB and VB deaths are associated only in Terai with $12.8 \%$ decrease in the deaths per $1 \mathrm{~m} / \mathrm{s}$ increase in wind speed. (Table 6)(Fig. 7). Lag type shows almost all of them following MA lag structure except one following GEO decay. Lag length vary significantly between Hill and Terai for VB hospitalization (1-45 days) whereas found consistent with 15 days for WB hospitalization (where wind speed is included in model). For other responses lag length ranged widely from 7 to 21 days.

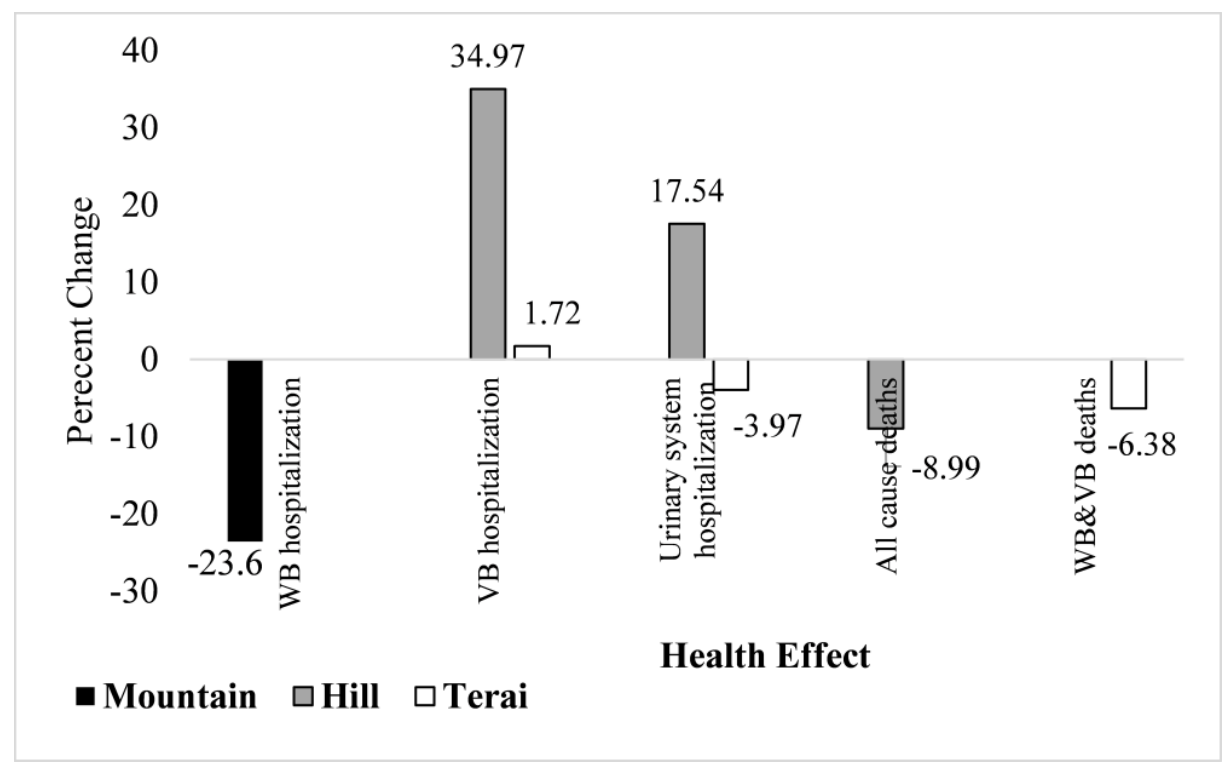

Fig. (7). Percent change in effects per $1 \mathrm{~m} / \mathrm{s}$ increase in wind speed. 


\subsection{Confounding Effects}

Daily hospitalizations and even deaths are found significantly associated with whether a day is a public holiday or not. In the present analysis, a holiday is represented by Saturday since in Nepal Saturday is a public holiday. Analysis of effects showed that a holiday is associated with reduced hospitalizations and all cause deaths with $11.8 \%$ to $37.5 \%$ decrease in hospitalization or death compared to weekdays. Even though the extents of effects are varied across regions and health effects, the effects are consistently in the same direction for all regions as well as for different health effects. This implies that a holiday reduces the chances of hospitalizations or even death (Table 7).

Table 7. Percent change in effects due to public holiday.

\begin{tabular}{|c|c|c|c|}
\hline Health Effect & Mountain & Hill & Terai \\
\hline WB hospitalization & $\mathrm{X}$ & $\begin{array}{c}-25.9 \\
{[-29.4 ;-22.3]}\end{array}$ & $\begin{array}{c}-11.8 \\
{[-15.9 ;-7.5]}\end{array}$ \\
\hline VB hospitalization & 一 & $\begin{array}{c}-29.4 \\
{[-42.1 ;-13.9]}\end{array}$ & $\begin{array}{c}-51.4 \\
{[-58.6 ;-42.9]}\end{array}$ \\
\hline Urinary system hospitalization & 一 & $\begin{array}{c}-37.5 \\
{[-44.7 ;-29.6]}\end{array}$ & $\begin{array}{c}-32.6 \\
{[-42.1 ;-21.7]}\end{array}$ \\
\hline HD hospitalization & 一 & $\begin{array}{c}-33.5 \\
{[-42.4 ;-23.1]}\end{array}$ & $\begin{array}{c}-23.9 \\
{[-30.9 ;-16.1]}\end{array}$ \\
\hline All cause deaths & $\mathrm{X}$ & $\begin{array}{c}-16.3 \\
{[-22.3 ;-9.8]}\end{array}$ & $\mathrm{X}$ \\
\hline
\end{tabular}

$\mathrm{X}$ implies not included in the model due to statistical insignificance.

— implies model not built.

Analysis also showed presence of annual trend effects which are statistically significant. WB hospitalization decreased annually for Terai by $12.3 \%$ but increased in Mountain and Hill regions by around $1 \%$. VB hospitalization decreased consistently across the regions with extent of decrease ranging between $8.5 \%$ and $15.2 \%$. In contrast, urinary system disease hospitalization increased by $5.5 \%$ to $10.5 \%$ across regions of Nepal. HD hospitalization decreased in Terai by $10.5 \%$ but increased in Hill region by $4.3 \%$ (in the analysis period). Considering trend effects on mortality, it is observed that all cause deaths decreased consistently across regions of Nepal by around 5.8\% except in Mountain where the decrease is by $55 \%$. Similarly, WB \& VB disease deaths also decreased in Hill and Terai regions by $17 \%$ to $28.9 \%$ except in Mountain (Table 8).

Table 8. Annual percent change in effects.

\begin{tabular}{|l|c|c|c|}
\hline Health Effect & Mountain & Hill & Terai \\
\hline WB hospitalization & 1.1 & 1.0 & -12.3 \\
& {$[-1.0 ; 10.1]$} & {$[-0.1 ; 2.0]$} & $-13.3 ;-11.3]$ \\
\hline VB hospitalization & - & -8.5 & -15.2 \\
& {$[-13.0 ;-3.9]$} & 10.5 & 5.5 \\
\hline Urinary system hospitalization & - & {$[7.3 ; 13.8]$} & $-1.6 ; 9.5]$ \\
\hline HD hospitalization & - & 4.3 & -10.5 \\
\hline All cause deaths & -55.0 & {$[-12.5 ;-8.5]$} \\
\hline WB \& VB deaths & {$[-72.0 ;-27.5]$} & {$[-7.5 .97-4.1]$} & -5.7 \\
& - & -17.0 & {$[-7.8 ;-3.4]$} \\
\hline
\end{tabular}

— implies model not built.

Seasonal dummies are created to account the effect of different seasons on health effects compared to winter season. However, all the seasonal effects (summer, spring and autumn) may not be statistically significant compared to winter in a specific model. Thus, if summer and spring seasons are statistically significant then the reference is the remaining seasons i.e. winter and autumn. The percent change in health effects according to type of disease burden, eco-belt and seasons are compared to remaining season (s). The sign and magnitude of seasonal effects are found quite dissimilar between health effects as well as between seasons. Examination of values revealed that the effects of summer and spring are actually negative compared to remaining seasons in a year for WB hospitalizations in Hill and Mountain with $10 \%$ to $33 \%$ decrease in summer compared to remaining months due to seasonal effect. Similarly, the coefficients are 
negative in case of urinary system hospitalization and WB \& VB deaths ( $8.6 \%$ to $49.7 \%$ decrease). However, in case of VB disease hospitalization, seasonal effects are found insignificant except in Hill or excluded due to multicollinearity effects. Similarly, other seasonal effects are shown and can be interpreted accordingly as shown in Table 9.

Table 9. Percent change in effects due to seasonal differences.

\begin{tabular}{|c|c|c|c|c|}
\hline Health Effect & Season & Mountain & Hill & Terai \\
\hline \multirow{3}{*}{ WB hospitalization } & Spring & $\begin{array}{c}-64.4 \\
{[-68.9 ;-59.2]}\end{array}$ & $\begin{array}{c}-6.8 \\
{[-12.0 ;-1.3]}\end{array}$ & $\mathrm{X}$ \\
\hline & Summer & $\begin{array}{c}-33.1 \\
{[-42.7 ;-22.0]}\end{array}$ & $\begin{array}{c}-10.1 \\
{[-14.0 ;-5.9]}\end{array}$ & $\mathrm{X}$ \\
\hline & Autumn & $\mathrm{X}$ & $\mathrm{X}$ & -10.3 \\
\hline \multirow{3}{*}{ VB hospitalization } & Spring & - & $\mathrm{X}$ & $\mathrm{X}$ \\
\hline & Summer & - & $\mathrm{X}$ & $\mathrm{X}$ \\
\hline & Autumn & - & $\begin{array}{c}70.2 \\
{[40.6 ; 106.3]}\end{array}$ & $\mathrm{X}$ \\
\hline \multirow{3}{*}{ Urinary system hospitalization } & Spring & - & $\mathrm{X}$ & $\mathrm{X}$ \\
\hline & Summer & - & $\begin{array}{c}-17.5 \\
{[-29.7 ;-3.1]}\end{array}$ & $\mathrm{X}$ \\
\hline & Autumn & - & $\begin{array}{c}-15.8 \\
{[-28.9 ;-0.3]}\end{array}$ & $\mathrm{X}$ \\
\hline \multirow{3}{*}{ HD hospitalization } & Spring & - & $\begin{array}{c}22.9 \\
{[9.1 ; 38.4]}\end{array}$ & $\mathrm{X}$ \\
\hline & Summer & - & $\mathrm{X}$ & $\mathrm{X}$ \\
\hline & Autumn & - & $\begin{array}{c}-8.4 \\
{[-18.4 ;-2.8]}\end{array}$ & -14.6 \\
\hline \multirow{3}{*}{ All cause deaths } & Spring & $\mathrm{X}$ & $\begin{array}{c}30.2 \\
{[17.1 ; 44.9]}\end{array}$ & $\mathrm{X}$ \\
\hline & Summer & $\mathrm{X}$ & $\begin{array}{c}9.2 \\
{[-1.0 ; 20.3]} \\
\end{array}$ & $\mathrm{X}$ \\
\hline & Autumn & $\mathrm{X}$ & $\begin{array}{c}12.2 \\
{[0.7 ; 25.0]}\end{array}$ & $\mathrm{X}$ \\
\hline \multirow{3}{*}{ WB \& VB deaths } & Spring & - & $\mathrm{X}$ & $\mathrm{X}$ \\
\hline & Summer & - & $\begin{array}{c}-49.7 \\
{[-72.7 ;-7.5]}\end{array}$ & $\mathrm{X}$ \\
\hline & Autumn & - & $\begin{array}{c}-30.3 \\
{[-58.9 ; 18.1]}\end{array}$ & $\mathrm{X}$ \\
\hline
\end{tabular}

$\mathrm{X}$ implies not included in the model due to statistical insignificance.

— implies model not built.

\subsection{Data Heterogeneity and Model Adequacy Tests}

Since eco-belt specific models are built, an examination of data heterogeneity within the eco-belts for model calibration would be informative. For the purpose, each eco-belts are further sub-divided in two groups. Since Mountain included only two hospitals two groups are formed containing a hospital in each group. Hill is divided into a group containing hospitals from Kathmandu Valley and another group containing hospitals from outside the valley. Lastly, Terai is subdivided into two groups containing two hospitals in each group. In groups containing two or more hospitals, groups are formed with hospitals with lesser assumed heterogeneity compared to hospitals of another group within a region. Correlations between temperature (the main climate variable in the study for EBD assessment) and health responses are computed for all health responses in each group along with an overall estimate for each eco-belt region as shown in the Table 10. The computed correlations showed nearly equal positive correlations between groups for all cause deaths in Mountain, WB, VB and HD hospitalizations and WB \& VB deaths in Hill, VB hospitalizations and WB and VB deaths in Terai. Similarly, positive correlations with considerable amount of deviations in the magnitude for WB hospitalization in Mountain, renal hospitalization and all cause deaths in Hill and WB hospitalization in Terai are detected. Some contrasting results are also detected in case of urinary system and HD hospitalizations and all cause deaths in Terai. The findings suggest that there exists definite similarities between groups (or hospitals) of each ecobelts regarding association between temperature and health responses which justifies the mehtodology of ecobelt-wise modeling adopted in the study. However, there are also some computed dissimilarities which could be due to differences other than climate related factors within the eco-belts of Nepal. 
Table 10. Correlations between health responses and temperature.

\begin{tabular}{|c|c|c|c|c|c|c|c|c|c|}
\hline \multirow{2}{*}{ Health Effect } & \multicolumn{3}{|c|}{ Mountain } & \multicolumn{3}{|c|}{ Hill } & \multicolumn{3}{|c|}{ Terai } \\
\hline & Overall & Group1 & Group2 & Overall & Group1 & Group2 & Overall & Group1 & Group2 \\
\hline WB & $\begin{array}{c}0.14 \\
(0.31)\end{array}$ & $\begin{array}{c}0.34 \\
(0.02)\end{array}$ & $\begin{array}{c}0.14 \\
(0.32)\end{array}$ & $\begin{array}{c}0.74 \\
(0.00)\end{array}$ & $\begin{array}{c}0.65 \\
(0.00)\end{array}$ & $\begin{array}{c}0.77 \\
(0.00)\end{array}$ & $\begin{array}{c}0.27 \\
(0.04)\end{array}$ & $\begin{array}{c}0.36 \\
(0.00)\end{array}$ & $\begin{array}{c}0.03 \\
(0.83)\end{array}$ \\
\hline VB & - & 一 & - & $\begin{array}{c}0.18 \\
(0.16) \\
\end{array}$ & $\begin{array}{c}0.19 \\
(0.14) \\
\end{array}$ & $\begin{array}{c}0.14 \\
(0.22) \\
\end{array}$ & $\begin{array}{c}0.50 \\
(0.00) \\
\end{array}$ & $\begin{array}{c}0.40 \\
(0.00) \\
\end{array}$ & $\begin{array}{c}0.53 \\
(0.00) \\
\end{array}$ \\
\hline Renal & - & - & - & $\begin{array}{c}0.48 \\
(0.00) \\
\end{array}$ & $\begin{array}{c}0.04 \\
(0.79) \\
\end{array}$ & $\begin{array}{c}0.46 \\
(0.00) \\
\end{array}$ & $\begin{array}{c}-0.11 \\
(0.42) \\
\end{array}$ & $\begin{array}{c}-0.37 \\
(0.00) \\
\end{array}$ & $\begin{array}{c}0.23 \\
(0.08) \\
\end{array}$ \\
\hline HD & - & - & 一 & $\begin{array}{c}0.08 \\
(0.52) \\
\end{array}$ & $\begin{array}{c}0.09 \\
(0.49) \\
\end{array}$ & $\begin{array}{c}0.03 \\
(0.83) \\
\end{array}$ & $\begin{array}{c}-0.04 \\
(0.76) \\
\end{array}$ & $\begin{array}{c}-0.21 \\
(0.11) \\
\end{array}$ & $\begin{array}{c}0.05 \\
(0.73) \\
\end{array}$ \\
\hline Deaths & $\begin{array}{c}0.26 \\
(0.07) \\
\end{array}$ & $\begin{array}{c}0.22 \\
(0.13) \\
\end{array}$ & $\begin{array}{c}0.20 \\
(0.17) \\
\end{array}$ & $\begin{array}{c}0.13 \\
(0.31) \\
\end{array}$ & $\begin{array}{c}0.14 \\
(0.30) \\
\end{array}$ & $\begin{array}{c}0.01 \\
(0.99) \\
\end{array}$ & $\begin{array}{l}0.08 \\
(0.6) \\
\end{array}$ & $\begin{array}{l}-0.21 \\
(0.87) \\
\end{array}$ & $\begin{array}{c}0.15 \\
(0.25) \\
\end{array}$ \\
\hline $\begin{array}{l}\text { WB \& VB } \\
\text { Deaths }\end{array}$ & - & - & - & $\begin{array}{c}0.11 \\
(0.42)\end{array}$ & $\begin{array}{c}0.09 \\
(0.47)\end{array}$ & $\begin{array}{c}0.11 \\
(0.40)\end{array}$ & $\begin{array}{c}0.28 \\
(0.03)\end{array}$ & $\begin{array}{c}0.24 \\
(0.06)\end{array}$ & $\begin{array}{c}0.23 \\
(0.07)\end{array}$ \\
\hline
\end{tabular}

Values in parentheses are $p$ values.

— implies model not built; CI implies confidence interval.

Model adequacy tests are done related to goodness of fit, residual analysis and multicollinearity. Multicollinearity arises due to high correlations between predictors and leads to inaccurate results. The variance inflation factor (VIF) quantifies the extent of multicollinearity present in a linear model and provides an index that measures how much the variance of an estimated regression coefficient is increased because of collinearity. Goodness of fit is checked through Omnibus test [42] and found to be good with $p$ values nearly zero for all the fitted models. Residual analysis showed errors distributed normally for some models and non-normal for rest of the models $(p$ value $<0.1)$. Fitted models showed standardized deviance residuals scattered randomly and with reasonably constant variances when plotted against predicted values. Screening of residual autocorrelations at different lags showed low values (mostly $<0.15)$ even though some were significant (but less than 0.3 ) which could be due to a very large sample size (1826 days) and were ignored also because the plot of standardized residual in time sequence showed no visible pattern with fairly constant spread (Fig. 8). There were no high multicollinearity among predictors in the models with VIFs smaller than 5 for all the predictors of the built models (less than 3 for 8 models; less than 4 for 12 models and less than 5 for all 14 models). There were one or two outliers in some of the built models which were ignored since they did not affected coefficients markedly.

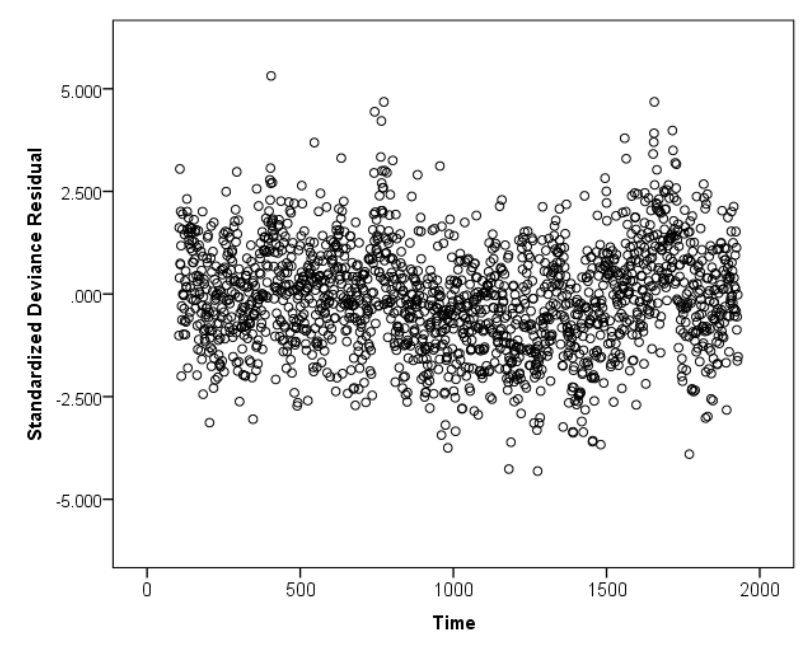

Fig. (8). Scatterplot of standardized deviance residual.

\subsection{EBD Attributable to Climate Sensitive Variable (Temperature)}

Estimated EBD due to temperature for different health burdens are given in Table 8. In the table, attributable fractions (AFs) along with total and attributable burdens (ABs) due to temperature rise are given. Burden per year is the average value obtained from available 17 years of morbidity and mortality data reported in annual reports of Department of Health Services (DoHS), Kathmandu (1997/98 - 2014/15). The computations of AFs and then ABs are 
based upon several assumptions. Minimum threshold values of average temperature for computation of AFs of waterborne diseases, vector-borne diseases, renal diseases, and disease specific mortality of water and vector-borne diseases are chosen as $5^{\circ} \mathrm{C}, 10^{\circ} \mathrm{C}, 10^{\circ} \mathrm{C}$ and $5^{\circ} \mathrm{C}$, respectively. In case of temperature taken as absolute difference, the threshold is $0^{\circ} \mathrm{C}$. Threshold values were chosen based upon literature review as well as observed values of temperature averages for the considered meteorological stations of Nepal in the study period and assumed that considered health effects below these threshold values are negligible. Attributable fractions and corresponding attributable burdens are computed separately for Mountain, Hill and Terai. In Mountain, results showed high AFs of around 0.38 - 0.41 for WB hospitalization and all cause deaths. In Hill region, among hospitalizations, AFs ranged between 0.24 and 0.52 with highest AF found for WB hospitalization and lowest AF found for urinary system hospitalization. Among deaths, very high AF (around 0.51) is obtained for WB \& VB deaths. However, AF for all cause death is found relatively much lower (0.12). In Terai region, AFs ranged in between 0.07 to 0.67 with highest obtained for VB hospitalization and lowest AF obtained for HD hospitalization/all cause deaths. Among deaths, AF for WB \& VB mortality is found to be 0.54. The attributable burdens due to temperature rise are given in the last column of the Table 11. It shows high annual attribution of WB diseases (2 lakh to 4 lakh) in Hill and Terai regions and around 64 thousand in Mountain annually. Similarly, other attributable burdens can be seen in the Table $\mathbf{1 1 .}$

Table 11. Attributable factors and attributable burdens.

\begin{tabular}{|c|c|c|c|c|c|c|c|}
\hline Region & Type & Response Variable & AF & $\begin{array}{c}\text { Burden/Year } \\
\text { (Outpatients) }\end{array}$ & $\begin{array}{c}\text { Burden/Year } \\
\text { (Inpatients) }\end{array}$ & $\begin{array}{c}\text { Total Burden / } \\
\text { year }\end{array}$ & $\begin{array}{c}\text { Attributable Burden / } \\
\text { year }\end{array}$ \\
\hline Mountain & Hospitalization & WB & 0.414 & 153344 & 2290 & 155634 & 64432 \\
\hline Mountain & Death & All cause & 0.3847 & - & - & 16 & 6 \\
\hline Hill & Hospitalization & WB & 0.5211 & 750831 & 10860 & 761691 & 396917 \\
\hline Hill & Hospitalization & VB & 0.4596 & 10816 & 268 & 11084 & 5094 \\
\hline Hill & Hospitalization & Urinary & 0.2424 & 88674 & 2158 & 90832 & 22018 \\
\hline Hill & Hospitalization & HD & 0.3007 & 63960 & 2557 & 66517 & 20002 \\
\hline Hill & Death & All Cause & 0.1233 & - & - & 75 & 9 \\
\hline Hill & Death & WB\&VB & 0.514 & - & - & 30 & 15 \\
\hline Terai & Hospitalization & WB & 0.3402 & 668450 & 9668 & 668450 & 227407 \\
\hline Terai & Hospitalization & VB & 0.6651 & 63946 & 1586 & 63947 & 42531 \\
\hline Terai & Hospitalization & Urinary & 0.2996 & 68419 & 1665 & 68419 & 20498 \\
\hline Terai & Hospitalization & HD & 0.0695 & 44043 & 1760 & 44043 & 3061 \\
\hline Terai & Death & All Cause & 0.0695 & - & - & 68 & 5 \\
\hline Terai & Death & WB\&VB & 0.5388 & - & - & 28 & \\
\hline
\end{tabular}

\section{DISCUSSION AND CONCLUSION}

Rise in average temperature or absolute difference in average temperature with its overall average is associated with increase in hospital morbidity and mortality of selected diseases as well as all cause mortality. This is found true for all the health effects considered in the study regarding the separate effects in different eco-belts of Nepal though the magnitude of effects varied marginally or significantly from one region to another and from one health effect to another. The effects ranged between $2.1 \%$ to $7.3 \%$ increase in the effects (WB, VB, urinary system hospitalizations and WB \& VB deaths) per $1{ }^{\circ} \mathrm{C}$ increase in average temperature and $0.9 \%$ to $8.2 \%$ increase in HD hospitalization and all cause deaths per $1{ }^{\circ} \mathrm{C}$ increase in the absolute difference of average temperature with its overall average of $20^{\circ} \mathrm{C}$. The presence of varied effects due to temperature can be due to various reasons such as difference in susceptibility of people between the regions, difference in practices regarding drinking water consumption, etc. The higher percentage rise in WB hospitalizations in Hill can be interpreted as people of Hill region in Nepal are relatively more prone to rise in temperature than those of Terai region which can be due to various reasons such as higher susceptibility of the people in the region, difference in practices regarding drinking water consumption, etc. Similarly, higher effect of rise in temperature on VB hospitalization in Terai can be interpreted as Terai being the hottest region in Nepal with relatively higher average temperature in all seasons, the effects of rise in temperature is also relatively higher since survival/transmission of bacteria and viruses that causes these diseases are relatively higher in the conditions that prevail in the Terai region of Nepal. Rise in average temperature is likely to spread infectious diseases to new places like places of Mountain region in Nepal.

Diverse and contrasting effects of rainfall are also revealed from the analysis with $-8.7 \%$ to $2.4 \%$ change in health effects per $1 \mathrm{~mm}$ increase in rainfall. This may be due to significant geographic/topographical variations between 
ecological belts of Nepal as well as other factors like differences in socio-economic conditions, development levels, levels of exposure and practices, vulnerability and adaptations, etc. One of the main reason of rise in WB hospitalizations in rainy season could be due to pathogen contamination in household water supply. This could be primarily due to mixing of contaminated rain water to drinking water source/storage through poor sanitation facilities/discharges or practices and mixing up waste materials to drinking water due to rainfall which is consistent with the findings in Hill with 2.4\% rise in WB hospitalization per $1 \mathrm{~mm}$ rise in rainfall.

In Mountain, revelation of negative association could be due to low contamination possibilities in household water in rainy season due to least or non-existence of mixing up phenomena through sanitation or other means with very low population and waste material generation. Moreover, it seems that rainfall actually cleans the environment including water storage/supply in the region. In Terai, people depend mainly upon ground water for drinking and other household purposes. In rainy season ground water is diluted with rainfall and due to large open fields of Terai belt, mixing up of waste materials and waste discharge to drinking water could be low. Thus, results suggest that chances of catching WB diseases during rainfall time is relatively low compared to dry season except during occurrences of natural disasters like floods due to extreme rainfall during when chances of infections and spread of WB diseases are naturally high. The results demonstrate that high rainfall actually prevents survival and transmission of carriers of VB diseases. Heavy rainfall may have catastrophic impacts on mosquito population since strong rainfall can sweep away their breeding sites [43]. The findings of varied effects due to rainfall on infectious diseases as observed in the present study between regions and between health effects are also evidenced through various studies conducted at different parts of the world. The findings of varied effects could be due to differences in pathogens, geographical regions, types of water supply, storage or source at different regions and seasonal atmospheric differences at different regions [44].

Effects due to relative humidity and wind are also found varied between health effects and regions. It is found that $-1.6 \%$ to $7.3 \%$ changes in health effects detected per $1 \%$ increase in relative humidity. Effects are found positive with magnitude in the range $0.4 \%$ to $7.3 \%$ increase in VB, urinary system and HD hospitalizations, all cause deaths and WB $\&$ VB deaths whereas negative and in the range $0.6 \%$ to $1.6 \%$ decrease in WB hospitalization per $1 \%$ rise in relative humidity. The positive effects of humidity on VB disease hospitalization could be due to higher moisture content in humid air which is favorable to survival and therefore transmission VB disease carriers whereas negative effects of humidity on WB hospitalization suggests a contrasting result which calls for further research in this area. The positive association between humidity and urinary system disease hospitalization may be partly due to increased chances of bacterial infections causing urinary tract infections and leading to urinary system problems in relatively more humid conditions.

Wind is found to be a principal factor affecting the transmission of pathogens of air borne diseases since pathogen are attached with dust particles and transported from one place to another by wind [45]. Examination of effects due to wind showed that increase in wind speed increases VB hospitalization though the magnitude of effects are substantially varied across regions (1.7\%-35\%). Substantially higher rate of effects of wind speed on VB hospitalization in Hill compared to Terai suggests that areas covered in Hill in the present study could be significantly highly polluted particularly with dust particles compared to the regions covered in Terai. Such conditions with higher contents of dust particles in ambient air are more favorable to pathogen transmissions. Additionally, increase in wind is associated with $23.6 \%$ decrease in WB hospitalization in Mountain, 9\% decrease in all cause deaths in Hill and $6.4 \%$ decrease in WB \& VB deaths in Terai per $1 \mathrm{~m} / \mathrm{s}$ increase in wind speed.

Analysis of results demonstrated that public holidays are associated with reduced hospitalizations compared to working days. This may be due to various regions. For instance, a holiday may decrease the possibility of infection due to reduced exposures and staying in relatively safe environment. People may be more relaxed and relatively tension free during holidays which can reduce the chances of hospitalization associated with heart diseases and risk of mortality associated with heart failures.

Analysis of EBD attributable to temperature rise with respect to different eco-belts showed substantial AFs in the range 0.38 to 0.41 in Mountain, 0.24 to 0.52 in Hill for hospitalizations, 0.12 to 0.51 in Hill for deaths, 0.07 to 0.67 for hospitalization and 0.07 to 0.54 for deaths in Terai. Among the highest AFs are found for VB hospitalization in Terai (0.67), WB hospitalization in Hill (0.52), WB \& VB deaths in Hill (0.51) and WB \& VB deaths in Terai (0.54).

Results of the study showed statistically significant effects due to climate variables on many disease burdens assessed by hospital inpatient morbidities and mortality with rise in surface air temperature and rise in deaths and heart disease morbidity with rising hotness and coldness i.e. extreme atmospheric conditions. Study findings demonstrated 
that substantial proportions of disease attributions can be linked to rise in surface air temperature which means that with estimated rise in average surface air temperature by around 0.20 to $0.25^{\circ} \mathrm{C}$ per decade for Nepal, climate change is bound to effect and increase public health burdens of Nepalese population, specifically in the absence of appropriate measures to counter the effects of climate change. Apart from addressing the main cause of global warming i.e. human activities that increase greenhouse gas concentration in air, through common and widespread use of alternate renewable and eco-friendly energy technologies, Nepal faces the challenge and need to improve preparedness and adaptation strategies like cleaner surroundings and practices, coping effectively with diseases through improvement of infrastructure and facilities, assessing and educating the vulnerable section of our society and enforcing regulations and laws to protect our environment as far as possible and feasible.

\section{CONFLICT OF INTEREST}

The authors confirm that this article content has no conflict of interest.

\section{ACKNOWLEDGEMENTS}

This paper is based on research financed under the Climate Change Research Grants Program implemented by the Nepal Academy of Science and Technology. The Program is a part of the Mainstreaming Climate Change Risk Management in Development study. This study is a component of Nepal's Pilot Program for Climate Resilience and is executed by the Ministry of Population and Environment (Nepal), financed by the Climate Investment Funds, administered by the Asian Development Bank with technical assistance from ICEM, METCON and APTEC.

We would like to extend our gratitude to all those involved in the study regarding data collection and entry and also to all the secondary data providers including the referred hospitals, Department of Hydrology and Meteorology (DHM), Kathmandu and Department of Health Services, Teku, Kathmandu; and Ministry of Health and Population, private hospitals and ethical approval providers for delivering approval/request letter for collecting data from hospitals and all others involved in the study. The authors acknowledge World Bank Climate Change Knowledge Portal information on historical climate data of Nepal for free internet access. Special thanks to Dr. Rajesh Dhoj Joshi, Kathmandu Model Hospital, Kathmandu for his work in the study, Prof. Dr. Azaya Bikram Sthapit, Global College of Management, Kathmandu, Prof. Dr. Shankar Prasad Khanal, Head, Central Department of Statistics, Tribhuvan University, Kirtipur and Prof. Dr. Ganga Shrestha, Academician, Nepal Academy of Science and Technology, Khumaltar for supporting us in conducting the research.

\section{REFERENCES}

[1] Haughton JT, Ding Y, Griggs DJ, et al. Climate change 2001: The scientific basis, Third assessment report; Intergovernmental panel on climate change. UK: Cambridge University Press 2001.

[2] Stocker TF, Qin D, Plattner GK, et al. Climate change 2013: The physical science basis, $5^{\text {th }}$ assessment report; Intergovernmental panel on climate change. UK: Cambridge University Press 2013.

[3] Chaudhary P, Aryal KP. Global warming in Nepal: Challenges and policy imperatives. J For Livelihood 2009; 8(1): 4-13.

[4] Ebi KL, Woodruff R, Von Hildebran A, Corvalan C. Climate change-related health impacts in the Hindu Kush-Himalayas. EcoHealth 2007; 4: 264-70.

[http://dx.doi.org/10.1007/s10393-007-0119-z]

[5] Shrestha AB, Wake CP, Mayewski PA, Dibb JE. Maximum temperature trends in the Himalaya and its vicinity: An analysis based on temperature records from Nepal for the period 1971-94. J Clim 1999; 12: 2775-86. [http://dx.doi.org/10.1175/1520-0442(1999)012<2775:MTTITH>2.0.CO;2]

[6] Shrestha AB, Wake CP, Mayewski PA, Dibb JE. Precipitation fluctuations in the Himalaya and its vicinity: An analysis based on temperature records from Nepal. Int J Clim 2000; 20: 317-27. [http://dx.doi.org/10.1002/(SICI)1097-0088(20000315)20:3<317::AID-JOC476>3.0.CO;2-G]

[7] Karmacharya J, Shrestha A, Rajbhandari R, Shrestha ML. Climate change scenarios for Nepal based on regional climate model RegCM3. Kathmandu: Department of Hydrology and Meteorology, Nepal Government 2007.

[8] Average monthly temperature for Nepal from 1960-1990 and 1990-2012. The World Bank Group 2016. Available from: http://sdwebx. worldbank.org/climateportal/

[9] Badu M. Assessing the impact of climate change on human health: Status and trends of malaria and diarrhea with respect to temperature and rainfall variability in Nepal. Kathmandu Univ J Sci Eng Technol 2013; 1: 96-105.

[10] Bhandari GP, Gurung S, Dhimal M, Bhusal CL. Climate change and occurrence of diarrheal diseases: evolving facts from Nepal. J Nepal Health Res Counc 2012; 10(22): 181-6.

[PMID: 23281447] 
[11] Regmi BR, Pandit A, Pradhan B, Kovats S, Lama P. Climate change and health in Nepal, Capacity strengthening in the least developing countries for adaptation to climate change; CLACC working paper 3, International Institute for Environment and Development, UK, 2008.

[12] Joshi HD, Dhimal B, Dhimal M, Bhusal CL. Public health impacts of climate change in Nepal. J Nepal Health Res Counc 2011; 9(1): 71-5. [PMID: 22929718]

[13] Hajat S, Kovats RS, Atkinson RW, Haines A. Impact of hot temperatures on death in London: a time series approach. J Epidemiol Community Health 2002; 56(5): 367-72.

[http://dx.doi.org/10.1136/jech.56.5.367] [PMID: 11964434]

[14] Giang PN, Dung V, Bao Giang K, Vinhc HV, Rocklöv J. The effect of temperature on cardiovascular disease hospital admissions among elderly people in Thai Nguyen Province, Vietnam. Glob Health Action 2014; 7: 23649. [http://dx.doi.org/10.3402/gha.v7.23649] [PMID: 25511886]

[15] Tian L, Qiu H, Sun S, Lin H. Emergency cardiovascular hospitalizations attributable to cold temperatures in Hong Kong. Circ Cardiovasc Qual Outcomes 2016; 9(2): 135-42. [http://dx.doi.org/10.1161/CIRCOUTCOMES.115.002410] [PMID: 26933049]

[16] Yao-Dong DU, Xian-Wei W, Xiao-Feng Y, Wen-Jun MA, Hui AI, Xiao-Xuan WU. Impacts of climate change on human health and adaptation strategies in South China. Adv Clim Change Res 2013; 4(4): 208-14. [http://dx.doi.org/10.3724/SP.J.1248.2013.208]

[17] Tong S, Wang XY, FitzGerald G, et al. Development of health risk-based metrics for defining a heatwave: a time series study in Brisbane, Australia. BMC Public Health 2014; 14: 435-44. [http://dx.doi.org/10.1186/1471-2458-14-435] [PMID: 24885799]

[18] Kovats RS, Campbell-Lendrum D, Matthies F. Climate change and human health: estimating avoidable deaths and disease. Risk Anal 2005; 25(6): 1409-18. [http://dx.doi.org/10.1111/j.1539-6924.2005.00688.x] [PMID: 16506971]

[19] Campbell-Lendrum D, Woodruff R. Comparative risk assessment of the burden of disease from climate change. Environ Health Perspect 2006; 114(12): 1935-41.

[PMID: 17185288]

[20] Bobb JF, Obermeyer Z, Wang Y, Dominici F. Cause-specific risk of hospital admission related to extreme heat in older adults. JAMA 2014; 312(24): 2659-67. [http://dx.doi.org/10.1001/jama.2014.15715] [PMID: 25536257]

[21] Checkley W, Epstein LD, Gilman RH, et al. Effect of El Niño and ambient temperature on hospital admissions for diarrhoeal diseases in Peruvian children. Lancet 2000; 355(9202): 442-50. [http://dx.doi.org/10.1016/S0140-6736(00)82010-3] [PMID: 10841124]

[22] Singh RB, Hales S, de Wet N, Raj R, Hearnden M, Weinstein P. The influence of climate variation and change on diarrheal disease in the Pacific Islands. Environ Health Perspect 2001; 109(2): 155-9. [http://dx.doi.org/10.1289/ehp.01109155] [PMID: 11266326]

[23] Raju DS, Kiranmayi P, Rachel K. Climate change and chronic kidney disease. Asian J Pharm Clin Res 2014; 7(2): 53-7.

[24] Hansen AL, Bi P, Ryan P, Nitschke M, Pisaniello D, Tucker G. The effect of heat waves on hospital admissions for renal disease in a temperate city of Australia. Int J Epidemiol 2008; 37(6): 1359-65. [http://dx.doi.org/10.1093/ije/dyn165] [PMID: 18710886]

[25] Kovats S, Ebi KL, Menne B. Methods of assessing human health vulnerability and public health adaptation to climate change; Health and global environmental change series 1, World Health Organization. Europe 2003.

[26] Campbell-Lendrum D, Woodruff R. Climate change: Quantifying the health impact at national and local levels; Environmental Burden of Disease Series, No 14. Geneva: World Health Organization 2007.

[27] Gasparrini A, Guo Y, Hashizume M, et al. Mortality risk attributable to high and low ambient temperature: a multicountry observational study. Lancet 2015; 386(9991): 369-75.

[http://dx.doi.org/10.1016/S0140-6736(14)62114-0] [PMID: 26003380]

[28] McCullagh P, Nelder JA. Generalized linear models. $2^{\text {nd }}$ ed. USA: Chapman and Hall Inc. 1989. [http://dx.doi.org/10.1007/978-1-4899-3242-6]

[29] Shrestha SL. Time series modeling of respiratory health admissions and geometrically weighted distributed lag effects from ambient particulate air pollution within Kathmandu valley, Nepal. Environ Model Assess 2007; 12: 239-51. [http://dx.doi.org/10.1007/s10666-006-9071-5]

[30] Shrestha SL. Particulate air pollution and daily mortality in Kathmandu Valley, Nepal: Associations and distributed lag. Open Atmos Sci J 2012; 6(1): 62-70. [http://dx.doi.org/10.2174/1874282301206010062]

[31] Aboutkidshealth. After the floods: Water-borne and vector-borne diseases. 2016 Available from: http://www.aboutkidshealth.ca/ en/news/newsandfeatures/pages/after-the-floods-water-borne-and-vector-borne-diseases.aspx

[32] Water Wise. Waterborne diseases factsheet 2016. Available from: http://www.waterwise.co.za/site/water/diseases/waterborne.html 
[33] WenMed. Malaria. 2016 Available from: http://www.webmd.com/a-to-z-guides/malaria-symptoms

[34] Lymphatic Filarisis WH. A handbook of practical entomology for national elimination programmes. Geneva: WHO library cataloguing-inpublication data 2013.

[35] Incubation period 2016. Available from: https://en.wikipedia.org/wiki/Incubation_period

[36] Prüss-Üstün A, Mathers C, Corvalán C, Woodward A. Introduction and methods: Assessing the environmental burden of disease at national and local levels; Environmental burden of disease series No 1. Geneva: World Health Organization 2003.

[37] Mellor PS, Leake CJ. Climatic and geographic influences on arboviral infections and vectors. Rev - Off Int Epizoot 2000; $19(1)$ : 41-54. [http://dx.doi.org/10.20506/rst.19.1.1211] [PMID: 11189725]

[38] Patz JA, Epstein PR, Burke TA, Balbus JM. Global climate change and emerging infectious diseases. JAMA 1996; 275(3): $217-23$. [http://dx.doi.org/10.1001/jama.1996.03530270057032] [PMID: 8604175]

[39] Portier CJ, Thigpen TK, Carter SR, et al. A human health perspective on climate change; A report outlining the research needs on the human health effects of climate change. USA: Interagency Working Group on Climate Change and Health 2010.

[40] Beck-Johnson LM, Nelson WA, Paaijmans KP, Read AF, Thomas MB, Bjørnstad ON. The effect of temperature on Anopheles mosquito population dynamics and the potential for malaria transmission. PLoS One 2013; 8(11): e79276. [http://dx.doi.org/10.1371/journal.pone.0079276] [PMID: 24244467]

[41] Wu X, Lu Y, Zhou S, Chen L, Xu B. Impact of climate change on human infectious diseases: Empirical evidence and human adaptation. Environ Int 2016; 86: 14-23 [http://dx.doi.org/10.1016/j.envint.2015.09.007] [PMID: 26479830]

[42] Landau S, Everitt BS. A handbook of statistical analyses using SPSS. USA: Chapman \& Hall/CRC Press LLC 2004.

[43] Kan H. Climate change and human health in China. Environ Health Perspect 2011; 119(2): A60-1. [http://dx.doi.org/10.1289/ehp.1003354] [PMID: 21288808]

[44] Herrador BR, Blasio BF, MacDonald E, et al. Analytic studies assessing the association between extreme precipitation or temperature and drinking water-related waterborne infections: a review. Environ Health 2015; 14(29): 1-12. [PMID: 25564290]

[45] Chen PS, Tsai FT, Lin CK, et al. Ambient influenza and avian influenza virus during dust storm days and background days. Environ Health Perspect 2010; 118(9): 1211-6. [http://dx.doi.org/10.1289/ehp.0901782] [PMID: 20435545]

C) Shrestha et al.; Licensee Bentham Open

This is an open access article licensed under the terms of the Creative Commons Attribution-Non-Commercial 4.0 International Public License (CC BY-NC 4.0) (https://creativecommons.org/licenses/by-nc/4.0/legalcode), which permits unrestricted, non-commercial use, distribution and reproduction in any medium, provided the work is properly cited. 